\title{
A spatial-explicit dynamic vegetation model that couples carbon, water, and nitrogen processes for arid and semi- arid ecosystems
}

\author{
Chi ZHANG ${ }^{1 *}$, ChaoFan $\mathrm{LI}^{1,2}$, Xi CHEN ${ }^{1}$, GePing LUO ${ }^{1}$, LongHui $\mathrm{LI}^{1}$, XiaoYu LI ${ }^{1}$, Yan YAN ${ }^{1,2}$, \\ Hua SHAO ${ }^{1}$ \\ ${ }^{1}$ State Key Laboratory of Desert and Oasis Ecology, Xinjiang Institute of Ecology and Geography, Chinese Academy of Sciences, \\ Urumqi 830011, China; \\ ${ }^{2}$ University of the Chinese Academy of Sciences, Beijing 100049, China
}

\begin{abstract}
Arid and semiarid ecosystems, or dryland, are important to global biogeochemical cycles. Dryland's community structure and vegetation dynamics as well as biogeochemical cycles are sensitive to changes in climate and atmospheric composition. Vegetation dynamic models has been applied in global change studies, but the complex interactions among the carbon $(\mathrm{C})$, water, and nitrogen $(\mathrm{N})$ cycles have not been adequately addressed in the current models. In this study, a process-based vegetation dynamic model was developed to study the responses of dryland ecosystems to environmental changes, emphasizing on the interactions among the $\mathrm{C}$, water, and $\mathrm{N}$ processes. To address the interactions between the $C$ and water processes, it not only considers the effects of annual precipitation on vegetation distribution and soil moisture on organic matter (SOM) decomposition, but also explicitly models root competition for water and the water compensation processes. To address the interactions between $\mathrm{C}$ and $\mathrm{N}$ processes, it models the soil inorganic mater processes, such as $\mathrm{N}$ mineralization/immobilization, denitrification/nitrification, and $\mathrm{N}$ leaching, as well as the root competition for soil $\mathrm{N}$. The model was parameterized for major plant functional types and evaluated against field observations.
\end{abstract}

Keywords: process-based model; arid ecosystem; C cycle; vegetation dynamics

Citation: Chi ZHANG, ChaoFan LI, Xi CHEN, GePing LUO, LongHui LI, XiaoYu LI, Yan YAN, Hua SHAO. 2013. A spatial-explicit dynamic vegetation model that couples carbon, water, and nitrogen processes for arid and semiarid ecosystems. Journal of Arid Land, 5(1): $102-117$.

Dryland ecosystems, including arid, semiarid, and dry, sub-humid areas (Reynolds et al., 2007), occupy around $47 \%$ of the earth's land area (Lal, 2001) and account for about one third of the global vegetation carbon (C) storage (Allen-Diaz et al., 1996). Recent studies have indicated that these ecosystems may currently act as a large $\mathrm{C}$ sink and play a more significant role in the terrestrial $\mathrm{C}$ balance than previously expected (Lal, 2001; Wohlfahrt et al., 2008; Rotenberg and Yakir, 2010). Former studies suggested that the biogeochemical cycles were sensitive to environmental changes (Smith et al., 2000). The evidence indicates there have been recent, significant changes in climate and atmosphere in major arid and semiarid regions of the world (Manabe and Broccoli, 1990; Cook et al., 2004; Sorg et al., 2012). One example lies in the extensive arid region of Central Asia, where over the past 20 years, significant increases in precipitation have been recorded (Xu and Wei, 2004). The responses of these dryland to global changes, however, are relatively complex in comparison to other regions because of the substantial climate change impacts on their community structure as well as their $\mathrm{C}$, water, and nitrogen $(\mathrm{N})$ processes, which are closely coupled to each other. Process-based models are effective tools in addressing these ecosystem complexities (Shen et

\footnotetext{
"Corresponding author: Chi ZHANG (E-mail: zc@ms.xjb.ac.cn) Received 2012-08-15; revised 2012-09-19; accepted 2012-10-10

(C) Xinjiang Institute of Ecology and Geography, Chinese Academy of Sciences, Science Press and Springer-Verlag Berlin Heidelberg 2013
} 
al., 2009; Tian et al., 2011), and have been widely used in global change studies (IPCC, 2012).

Altered dryland community structures could have significant impacts on ecosystem functions. Therefore, it is important to consider vegetation dynamics when modeling the effects of global changes on dryland ecosystems (Notaro, 2008; Shao and Zeng, 2011). A vegetation dynamic model, PALS (Reynolds et al., 2000; Shen et al., 2005), has been developed to study the impacts of environmental changes on the community structure and ecosystem functions (e.g. net primary productivity or NPP) of arid ecosystems in the North American deserts. However, because the PALS is a non-spatial model and does not consider forest ecosystems, it is difficult to be applied in regional studies. There are several types of spatial-explicit vegetation dynamic models for regional or global scale researches. Ecophysiological-based static models, like BIOME 3 (Haxeltine and Prentice, 1996), determine the competiveness of different PFTs by comparing their potential NPPs under equilibrium status. Such static approaches are restricted to steadystate condition and cannot simulate ecosystem succession in response to global changes. Process-based dynamic vegetation models (PDVM) explicitly simulate vegetation competitions for resources such as light, water, and soil nutrients. Some PDVM, like HYBRID 3 (Friend et al., 1997), simulate ecosystem processes in the individual plant scale. These models are computationally intensive and are generally limited to site level studies. A simplification strategy is to assume even-aged population structure for any PFTs in a community, so that a PFT population can be represented by an average individual plant (AIP) and the number of living plants (Sitch et al., 2003). The first step in developing an effective regional vegetation dynamic model for dryland is to choose a simplification approach that balances modeling accuracy and simulation efficiency, based on the characteristics of the arid and semiarid ecosystems.

An important characteristic of the stressed ecosystems like the dryland is that a small environmental change such as air pollution or precipitation increase has the potential to trigger a total state shift (Scheffer et al., 2001). Due to the intense interactions among plant populations and between vegetation and the abiotic environments, ecological and biogeochemical processes are closely coupled in arid areas. These processes are under the control of multiple environmental factors, such as precipitation (Austin et al., 2004), temperature (Braswell et al., 1997), and $\mathrm{N}$ deposition (Ladwig et al., 2012). The effects of one environmental factor could be influenced by changes in another, resulting in complex, interactive effects from multiple, global changes in the dryland ecosystem. Drought stress, for example, may be ameliorated by elevated atmospheric $\mathrm{CO}_{2}$ concentration (Drake et al., 1997), while the $\mathrm{CO}_{2}$ fertilization effect could be reduced by the soil $\mathrm{N}$ deficit (Shaw et al., 2002). Gutierrez and Whitford (1987) found that the growth of desert vegetation was stimulated by water supplementation in the first year, but the response was reduced in the second year due to depletion of soil available $\mathrm{N}$. To study the impact of global changes on dryland ecosystems, a model should couples the major biogeochemical cycles-water, $\mathrm{C}$, and $\mathrm{N}$ processes. However, many popular vegetation dynamic models, such as the LPJ (Sitch et al., 2003), OCHIDEE (Krinner et al., 2005), or IBIS (Foley et al., 1996), tend to overlook the $\mathrm{N}$ processes and oversimplify interactions between the $\mathrm{C}$ and water processes. Although the IBIS v2.1 models $\mathrm{N}$ mineralization, it does not address the mechanisms of $\mathrm{N}$ limitation on the $\mathrm{C}$ processes. Many dryland ecosystem models ignore the N cycle (e.g. Walker and Langridge, 1996; Quevedo and Frances, 2008).

Despite its importance to dryland ecosystems, the interactions between plant and water have not been adequately addressed in most vegetation dynamic models. For example, while annual precipitation is an important climatic constraint on vegetation dynamics, it is not considered as a bioclimatic parameter in popular vegetation dynamic models, such as the LPJ, OCHIDEE, BIOME 3, or IBIS. Most models either overlook or oversimplify root competition for water. IBIS (Foley et al., 1996), for example, assumes that precipitation is first accessed by grass before available to woody plants. In reality, water supply to a plant is related to the water demand by the plant's transpiration, its root surface area and architecture (i.e. vertical distribution of root in the soil), and the moisture distribution in the soil (Feddes and Raats, 2004). The LPJ 
model has more realistic root competition scheme than other models. It divides the soil profile into two layers, and allows different plant functional types (PFT) to have different vertical root distributions in the soil layers, so that the water supply to a PFT is affected by the distribution of soil moisture as well as the root mass in the soil layers (Sitch et al., 2003). The LPJ model, however, requires the users to define the root fractions in each of the two fixed soil layers $(0.5 \mathrm{~m}$ upper and $1 \mathrm{~m}$ lower) for each PFT. Considering the diverse root architectures and the fast root dynamics of the desert plants, a more flexible approach should be developed to address the root distribution pattern in detail. More importantly, LPJ, like most other models, ignored the effects of water compensation when modeling water uptake by root. There is growing experimental evidence that plants, especially desert plants, can compensate for water stress in one part (i.e. a soil layer) of the root zone by taking up water from parts of the root zone where water is available (Taylor and Klepper, 1978; Hasegawa and Yoshida, 1982; English and Raja, 1996; Stikic et al., 2003; Leib et al., 2006). In LPJ, however, the potential transpiration is distributed over the root zone proportionally to root density, and is only locally reduced depending on water availability in each soil layer. Finally, LPJ assumes that the soil organic matter (SOM) decomposition rate increasing linearly with soil moisture. This assumption oversimplifies the non-linear effects of soil moisture on soil organic matter decomposition (Paul, 2001).

Simulating ecosystem processes in detail usually results in intensive computation. To conduct spatial simulations across heterogeneous landscape, we need to find a way to improve model efficiency while maintain its accuracy. Current vegetation dynamic models, like the LPJ, usually segment the study region into even-sized grids, each of which has relatively homogenous internal environments (soil, topography, climate and atmospheric conditions). In these models, all lands are treated equally, without considering their specific location and biogeophysical characteristics. However, the desert plains and mountain regions of the dryland has distinct local landscape heterogeneity. While the climate in a mountain region could change significantly in a very short distance (e.g. several kilometers from the mountaintop to valley), climate condition could be relatively stable across large areas (hundreds of kilometers) in a desert plain that consists of various land-use types (e.g. croplands, settlements and undisturbed deserts). To improve simulation efficiency, the mountain region and desert plain should be treated differently in spatial segmentation.

In this study, focusing on the structural characteristics of and the intense water-C-N interactions in the arid and semiarid ecosystems, a spatially explicit ecosystem model was paired with a vegetation dynamic module (AEM-DV). Unlike most other vegetation dynamic models, the AEM-DV considers the $\mathrm{N}$ cycle, which is coupled to the $\mathrm{C}$ cycle through the stoichiometry of plant organs and SOM. To address the interactions among the $\mathrm{C}$, water, and $\mathrm{N}$ processes, the AEM-DV (1) treats the annual precipitation as a major bioclimatic constraint on vegetation distribution, (2) has detailed root competition (for water and soil N) procedures, and (3) models the non-linear effects of water and $\mathrm{N}$ stresses on SOM decomposition. Furthermore, unlike the annual allocation scheme of the LPJ model, the AEM-DV simulates allocation in a daily time-step. To improve simulation efficiency, a more flexible segmentation approach, in comparison with the traditional evenly gridding method, is developed to address the heterogeneous environmental conditions in the arid and semiarid regions. The AEM-DV was parameterized for major PFTs and evaluated against field observations.

\section{Model description}

\subsection{Choosing an appropriate modeling approach for dryland ecosystems}

Models are abstracts of reality. The degree of model simplification should be determined according to the research objectives. As mentioned above, there are several types of process-based vegetation dynamic modeling approaches - the ecophysiological-based static models (e.g. the BIOME 3), the individual-based PDVMs (e.g. the HYBRID 3), and the AIP-based PDVMs (e.g. the LPJ). Based on the characteristics of the arid ecosystems, we tried to find a modeling approach that can fully address the important ecosystem structure and processes in dryland, while as simple as possible for efficient regional 
simulations. An important difference between the dryland and other ecosystems is the canopy structure, which strongly influences water and energy partition processes. While the more humid ecosystems like forest usually have closed canopies, desert plant community is characterized by open canopy structure (Aguiar and Sala, 1999). Yang et al. (2001) found that ignoring the heterogeneity in the canopy structure could result in up to $30 \%$ overestimation of the canopy-intercepted solar radiation, when simulating energy partition in an open-canopied ecosystem. Therefore, a dryland ecosystem model should be able to estimate canopy coverage. Because most ecophysiological-based static models do not address plant structure-tree height, stem diameter, and crown size, they are unable to estimate canopy coverage. To estimate canopy coverage, the PALS model assumed a constant leaf area index (LAI) for the crown of a plant functional type (PFT) (Reynolds et al., 2000). Such an assumption, however, is questionable, given the fact that the morphology and structure of desert plants are highly variable in response to environmental changes (Xu et al., 2007). The individual-based PDVMs and AIP-based PDVMs that explicitly model plant structure could produce more realistic canopy coverage estimations. The individual-based PDVMs, which model the life cycle of each individual tree in a plant community, are too computationally intensive for regional studies. Sitch et al. (2003) showed that the AIP-based PDVM approach could significantly improve the computational efficiency while maintaining an acceptable accuracy in simulating ecosystem functioning. Because the even-aged population assumption is valid for most arid ecosystems, where perennial seedlings can almost only be established in abnormally moist years, resulting in even-aged stand structure (Ackerman, 1979; Vasek, 1980), the AEM-DV adopts the AIP-based PDVM approach as described by Sitch et al. (2003).

\subsection{A flexible segmentation method for efficient simulations across heterogeneous landscapes}

Figure 1A shows the hierarchical structure of dryland as modeled by the AEM-DV. To account for spatial heterogeneity, we segmented the study region into multiple patches. A patch was assumed to be spatially homogeneous in terms of biogeophysical characteristics (e.g. latitude, elevation, soil properties), and the ecosystems in the same patch share a common set of environmental conditions. Table 1 lists the required environmental drivers and biogeophysical information for model inputs. According to these inputs, AEM-DV estimates other important biogeophysical variables (e.g. daylength) (see Appendix for further detail). Unlike the LPJ that segments the study region into evenly sized grids, patches in the AEM-DV could have the same or different shapes and sizes. In arid and semiarid regions, mountain areas usually have larger ecosystem diversity and higher spatial heterogeneity in topography and climate than the desert plains. The flexibility in segmentation helps to improve simulation efficiency by tailoring the patch's size and shape in accordance to local landscape pattern. In most dynamic vegetation models, a grid is occupied by a single land-use type. In contrast, a patch in the AEM-DV can have one or more land-use types, including non-vegetated lands (e.g. glaciers, water bodies and bare rocks), a natural ecosystem where multiple PFTs could coexist, and possibly some managed ecosystems (e.g. cultivated land or plantations) where single PFT is cultivated (Fig. 1A). The relative coverage of each land-use types in a patch is recorded and used to determine the overall biogeochemical cycles in a patch.

Table 1 Spatial datasets as model inputs

\begin{tabular}{|c|c|c|}
\hline Inputs & Unit & Description \\
\hline Soil clay content & $\%$ & \multirow{17}{*}{ Biogeophysical base maps } \\
\hline Soil sand content & $\%$ & \\
\hline Soil silt content & $\%$ & \\
\hline Soil depth & $\mathrm{m}$ & \\
\hline Soil acidity & $\mathrm{pH}$ & \\
\hline Soil bulk density & $\mathrm{g} / \mathrm{cm}^{3}$ & \\
\hline Elevation map & $\mathrm{m}$ & \\
\hline Aspect map & degree & \\
\hline Slope map & degree & \\
\hline Daily precipitation & $\mathrm{mm}$ & \\
\hline Daily maximum temperature & ${ }^{\circ} \mathrm{C}$ & \\
\hline Daily minimum temperature & ${ }^{\circ} \mathrm{C}$ & \\
\hline Daily average temperature & ${ }^{\circ} \mathrm{C}$ & \\
\hline Daily mean relative humidity & $\%$ & \\
\hline Daily mean solar radiation & $\mathrm{W}$ & \\
\hline Atmosphere $\mathrm{CO}_{2}$ concentration & ppmv & \\
\hline $\mathrm{N}$ deposition $\left(\mathrm{NH}_{\mathrm{x}}\right.$ and $\left.\mathrm{NO}_{\mathrm{y}}\right)$ & $\mathrm{g} \mathrm{N} / \mathrm{m}^{2} \cdot \mathrm{a}$ & \\
\hline
\end{tabular}




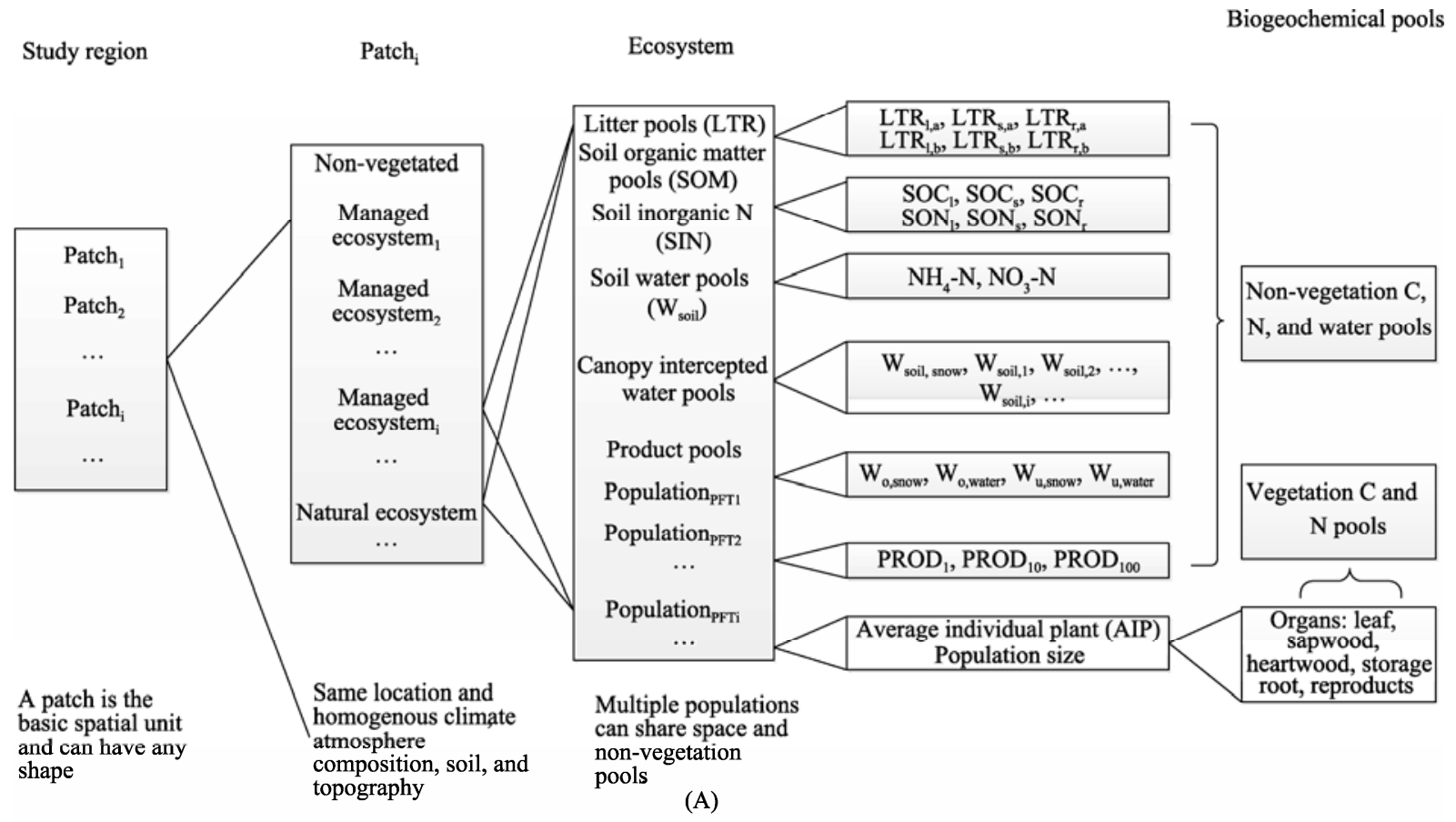

(a) Water balance

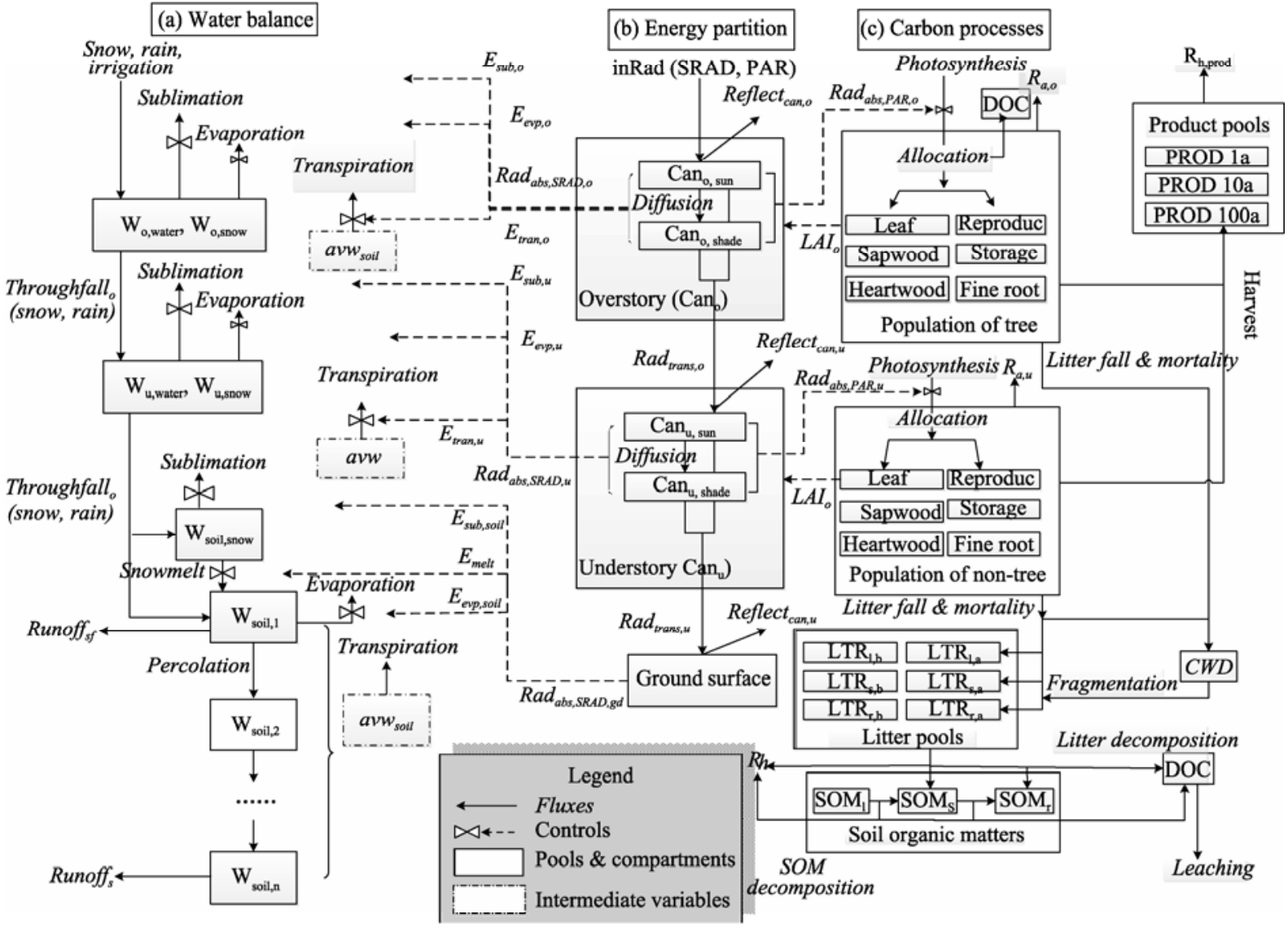

Note: Subscriptions " $o$ " and " $u$ " denote overstory and understory, respectively.

(B)

Fig. 1 Ecosystem structure and processes as modeled by AEM-DV. (A) Model structure, (B) Coupled energy, water, and C processes. 


\subsection{General description of the ecosystem processes modeled by the AEM-DV}

The AEM models ecosystem processes in a daily time-step. Different PFT populations may coexist in an ecosystem, competing for light, water, and nutrients. The dominance of a PFT in a plant community is determined by its relative competiveness under the local environment. Following the LPJ, a PFT population is represented by an AIP and the population density, which is updated by the population dynamic processes (seedling establishment and mortality) with an improved bioclimatic procedure that treats the annual precipitation as a major bioclimatic constraint. A PFT will be allowed to establish in the Spring only if the annual precipitation exceeds its minimum requirement ( $P P T_{\text {min,estab }}$; Appendix Table A1). If the long-term (20-a running mean) annual precipitation of a site becomes lower than the minimum precipitation threshold ( $\left.P P T_{\text {min,mort }}\right)$ of a PFT, the population will die out. A detailed description of the vegetation dynamic procedure is found in the Appendix.

In the AEM-DV, an AIP (average individual plant) is composed of four structural organs: leaves, fine roots $(f r t)$, sapwood $(s w d)$, and heartwood ( $h w d$; only in woody PFT), and a reproductive organs (reprod) (Fig. 1B). In woody PFT, swd and hwd together compose the stem (aboveground part) and coarse root (crt; belowground part). The AEM-DV assumes a fixed ratio $\left(\eta_{\text {stmcr }}\right)$ between the stem and the coarse root, and fixed C:N ratios for the organs of a certain PFT. AEM-DV also has internal storage pools for $\mathrm{C}\left(C_{\text {store }}\right)$ and $\mathrm{N}\left(N_{\text {store }}\right)$ for unallocated photosynthate and mobile N. Photosynthate and nutrients are allocated to living structural organs (leaf, sapwood, and fine root) to maintain plant form, which is dynamically updated according to empirical allometric equations and/or the Pipe theory (Shinozaki et al., 1964; Chiba, 1990). Unlike the annual allocation scheme of the LPJ model, $\mathrm{C}$ dynamic of an organ is updated daily in the AEM-DV (see below). Since the C:N ratio of litter and dead wood are usually larger than live tissues, tissue turnover as well as maintenance respiration may result in $\mathrm{N}$ resorption. The productivity, growth, litterfall, and mortality of AIP are modeled mechanistically in a daily time-step.
Besides the vegetation biomass pools, AEM-DV defines a converging cascade of 17 progressively more recalcitrant litter and organic matter pools (including seven litter pools): four aboveground litter pools, i.e. coarse woody debris (CWD), aboveground labile litter (LTRa,l), aboveground slow litter (LTRa,s), aboveground resistant litter (LTRa,r); three belowground litter pools, i.e. belowground labile litter (LTRb,l), belowground slow litter (LTRb,s), and belowground resistant litter (LTRb,r); three soil organic matter pools, i.e. labile SOM (SOMl), slow SOM (SOMs), resistant SOM (SOMr); a soil dissolved organic C pool (DOC); a dissolved organic N pool (DON); and three product pools - PROD1, PROD10, PROD100, each with different turnover rates (i.e. 1 year, 10 years, and 100 years, respectively), which store harvested woody (e.g. furniture and fiber) and food products. Furthermore, there are two soil inorganic $\mathrm{N}$ pools (i.e. $\mathrm{SIN}$ ) $-\mathrm{NH}_{4}{ }^{+}$and $\mathrm{NO}_{3}{ }^{-}$. A converging cascade decomposition scheme similar to that of BIOME-BGC v4.1 (Running and Coughlan, 1988; Thornton et al., 2005) is used to model the decomposition of detritus pools (Fig. 1B). N loss through trace gas emission is addressed with a nitrification-denitrification procedure.

The canopy structure of an ecosystem is stratified into two layers - the overstory $\left(\mathrm{Can}_{\mathrm{o}}\right)$ composed by crowns of woody PFTs and the understory $\left(\mathrm{Can}_{\mathrm{u}}\right)$ composed by leafs of non-woody PFTs. For each canopy layer, ecological processes of the sunlit and shaded fractions are modeled separately (Fig. 1B). The biogeochemical processes of $\mathrm{C}$ and water are coupled through energy-balance processes (Fig. 1B). Canopy radiation transmission and energy partitioning is estimated with the Beer-Lambert Law (Ingle and Crouch, 1988). In order to simplify the energy partition process, the AEM-DV assumes that crowns of plants belonging to the same canopy level do not overlap; the incipient solar energy is either reflected or partitioned among the two canopy layers and the soil surface. The incipient precipitation may also be intercepted by the two canopy layers, with the rest either lost by evapotranspiration and runoff, or partitioned among the multiple soil layers.

AEM-DV can output water, $\mathrm{C}$, and $\mathrm{N}$ pools and fluxes in each of the AIP, population, ecosystem, and 
patch levels (Fig. 1A) in daily time-step. The structure and functions of the lower levels are aggregated to derive the behavior of a higher level. For example, ecosystem functions $(F u c)$ are calculated as:

$$
\begin{aligned}
\text { Func }_{e \cos y s} & =\sum_{i \in e \cos y s} \text { Func }_{\mathrm{p}, i} \\
& =\sum_{i \in e \cos y s} \text { Func }_{i} \times \text { Density }_{i} .
\end{aligned}
$$

Where, Func $c_{\text {ecosys }}$ and Func $p$,i are the functions of the ecosystem (ecosys) and the population of PFT $i$, respectively; $F_{\text {unci }}$ is the function of AIP that represents the PFT $i$.

Following sections focus on the procedures that are unique to the AEM-DV, including the daily allocation of $\mathrm{C}$ and $\mathrm{N}$, the root competition for water and $\mathrm{N}$ in the soil, the non-linear influence of water stress on SOM decomposition, and the dynamic of soil inorganic nitrogen pools. Other processes are modeled in ways similar to most other ecosystem models as described in Appendix.

It should be indicated that: in Fig. 1: (a) Water balance, W refers to water pools, where subscriptions $o, u$, and soil denote water pools stored in the canopy of overstory (trees), canopy of understory (grass and shrub), and soil, respectively. Subscriptions water and snow denote canopy intercepted rainwater and canopy intercepted water equivalent snow, respectively. $W_{\text {soil }, 1,}$ $W_{\text {soil, }, 2}$, and $W_{\text {soil, } n}$ represent water pools of different soil layers. $a v w$ refers to the amount of soil water that is available for transpiration. Subscriptions $s f$ and $d r$ denote surface and drainage runoff, respectively; (b) Energy partition, among canopies and ground surface, inRad is the incipient solar radiation. Subscriptions $S R A D$ and PAR represent total solar radiation and photosynthetic active radiation, respectively. Can refers to canopy. Subscriptions sun and shade refer to sunlit and shaded leaf/canopy, respectively. Subscriptions $o, u$, and $g d$ refer to overstory, understory, and ground surface (including snow and bare soil), respectively. $\operatorname{Rad}_{a b s}$ refers to absorbed solar energy that drives water processes (converted to latent heat) or photosynthesis. $E_{\text {sub }}, E_{\text {melt }}, E_{\text {evp }}$, and $E_{\text {tran }}$ represent latent heat for sublimation (of snow), snowmelt, evaporation, and transpiration, respectively. These processes are driven by $\operatorname{Rad}_{a b s, S R A D}$; and (c) Carbon processes, DOC, LTR, CWD, SOM, and PROD represent dissolved organic $\mathrm{C}$ pool, litter pool, coarse woody debris, soil organic matter, and ecosystem product pools (with 1-, 10-, and 100-a residence time), respectively. $R_{a}$ and $R_{h}$, represent autotrophic respiration and heterotrophic respiration, respectively. Subscriptions $o$ and $u$ denote overstory and understory, respectively.

\subsection{Daily allocation of $\mathrm{C}$ and $\mathrm{N}$}

Similar to the LPJ model, photosynthate is allocated to maintain the plant form, i.e. the biomass ratio among the leaf, sapwood, and fine root, while the non-live tissues such as heartwood will not be changed by allocation (Sitch et al., 2003). A non-woody plant is assumed to have fixed form that is defined by PFT specific parameters, while a woody plant's form is updated dynamically, based on three constraints: 1) foliage area is assumed to be linearly proportional to sapwood area at breast height; 2) the ratio of foliage and fine root $\mathrm{C}$ mass is fixed; 3 ) the allometric relationship between diameter at breast height (DBH, meter) and woody $\mathrm{C}$ mass is fixed (see the Appendix). Whenever the biomass of a tree changes (e.g. due to disturbances, maintenance respiration, turnover, and photosynthate allocation), its tree form will change. Because estimating tree form requires intensive computation, the AEM-DV only update tree form at the beginning of each year, assuming it to remain unchanged throughout the year. The AEM-DV, however, models allocation in a daily time-step. This is different from the annual allocation scheme in the LPJ model, which causes abrupt changes in vegetation $\mathrm{C}$ and plant structure at the end of each year. The plant and canopy structures are updated following daily allocation (see the Appendix).

Following $\mathrm{C}$ allocation, $\mathrm{N}$ is partitioned so as to maintain constant $\mathrm{C}: \mathrm{N}$ ratios of each organ. If the demand for $\mathrm{N}$ exceeds $N_{\text {store }}$, plant growth is limited and excessive $\mathrm{C}$ is added to $C_{\text {store }}$. In this case, a fraction of the increased $C_{\text {store }}\left(G P P_{\text {excs }}\right)$ enters the soil as dissolved organic $\mathrm{C}$, stimulating microbial processes and enhancing the rate of $\mathrm{N}$ mineralization (Schimel and Weintraub, 2003; Montaño et al., 2007).

\subsection{Modeling root structure and their competition for soil water}

The vertical patterns of root system and soil moisture are addressed by dividing the soil (and roots) into 
multiple layers. In contrast to most other models (like the LPJ) that predefine a fixed number of soil layers, the AEM-DV allows users to define the number and thickness of soil layers according to their study objectives. The default is six soil layers, having the depths of 0-10, 10-20, 20-40, 40-60, 60-80, and 80-100 cm, in a top-down sequence to a total depth of $1 \mathrm{~m}$. Unlike the LPJ and PALS model that requires user to define the fraction of root distributed in each soil layer, the AEM-DV models the vertical distribution of root using an asymptotic equation $Y=1-\beta^{\mathrm{d}}$ (Gale and Grigal, 1987), where $Y$ is the cumulative root fraction (0-1) from the soil surface to the depth $d$ (in centimeters), and $\beta$ is the fitted extinction coefficient taken from Jackson et al. (1997). Therefore, the root fraction in soil layer $n$ (Rootfract $\left.{ }_{i, n}\right)=Y_{i, n}-Y_{i, n-l}$, where $i$ denots the PFT. AEM-DV can also use a parametric modeling approach, similar to PALS (Kemp et al., 1997), to simulate root distribution pattern (e.g. of phreatophyte) that cannot be modeled with Gale and Grigal's equation.

Water extracted from soil by plant roots supports transpiration. To estimate water uptake from soil layer $n$ by each PFT population $i$, AEM-DV first calculates the water demand for potential transpiration of the plant $\left(\operatorname{Ptran}_{i}, \mathrm{~mm} /\right.$ day $)$. Ptran $_{i}$ is driven by the remaining leaf-absorbed shortwave energy after leaf-intercepted water pools are depleted by sublimation and evaporation. The rate of $\operatorname{Ptran}_{i}$ is calculated using the Penman-Monteith approach, where canopy resistance $\left(r_{c}\right)$ is largely controlled by stomatal conductance, which is related to photosynthesis. Photosynthesis is controlled by the leaf-absorbed PAR, ambient $\mathrm{CO}_{2}$ concentration, and environmental factors such as temperature and water potential of the foliage (see the Appendix).

Once the $\operatorname{Ptran}_{i}$ of the entire plant is determined, AEM-DV will estimate the amount of water that needs to be extracted from each soil layer $(n)$ by the root systems of the PFT $i\left(\right.$ Ptran $_{i, n}, \mathrm{~mm} /$ day). To account for water-stress compensation (i.e. water stress in one part of the root zone can be compensated by enhanced water uptake from other wetter parts), AEM-DV assumes that the water demand (i.e. $\operatorname{Ptran}_{i, n}$ ) is proportional to a weighted stress index, which is a function of both relative root density (i.e. Rootfract $_{i, n}$ ) and available water $\left(A V W_{i, n}, \mathrm{~mm}\right.$; see the Appendix).

$$
\left.\begin{array}{l}
\text { Ptran }_{i, n}=\text { Weight }_{i, n} \times \text { Ptran }_{i}, \\
\text { Weight }_{i, n}=\frac{\text { Rootfract }_{i, n}^{a} \times A V W_{i, n}}{\sum_{n=1}^{N} \text { Rootfract }_{i, n}^{a} \times A V W_{i, n}}
\end{array}\right\}
$$

in which we set $\alpha$ to 1.0 , a value between the theoretical estimation of $>1.1$ (van der Ploeg et al., 1978; Passioura, 1985) and the experimentally derived value of 0.5 (Ehlers et al., 1991).

Next, AEM-DV estimates the actual ecosystem transpiration rate $\left(\operatorname{Tran}_{\text {ecosys }, n}, \mathrm{~mm} /\right.$ day) from the soil layer $n$ by comparing the available soil water $\left(A V W_{n}\right)$ and the water required to support the potential ecosystem transpiration ( Ptran $_{\text {ecosys }, n}=\sum_{i \in \text { ecosys }} \operatorname{Ptran}_{i, n}$ ).

$$
\operatorname{Tran}_{\text {ecosys, } n}=\operatorname{Min}\left(A V W_{n}, \text { Ptran }_{\text {ecosys }, n}\right) \text {. }
$$

$\operatorname{Tran}_{\text {ecosys }, n}$ is then allocated to the roots in the soil layer $n$, representing root competition for water. When competing for water resources, the water available to plant $i$ (i.e. $A V W_{i, n}$ ) is linearly proportional to the competitiveness of its root in the soil layer. The competitiveness of root $i$ in the soil layer $n\left(\right.$ Rtcomp $\left._{i, n}\right)$ is linearly proportional to its active surface area $\left(\right.$ Rtsurf $\left._{i, n}, \mathrm{~m}^{2}\right)$ :

$$
\left.\begin{array}{rl}
\operatorname{Tran}_{i c, n}= & \operatorname{Min}\left(A W_{\text {soil }, n}, \text { Ptran }_{l c, n}\right), \\
A V W_{i, n}= & \operatorname{Rtcompi}_{i, n} \times A V W_{\text {soil }, n}, \\
\operatorname{Rtcompi}_{i, n}= & \frac{\operatorname{Rtsurf}_{i, n}}{\sum_{i \in l c} \operatorname{Rtsurf}_{i, n}}, \\
\operatorname{Rtsurf}_{i, n}= & C_{\text {root }, i_{i}} \times \text { Density }_{i} \times \text { Rootfract }_{i, n} \times \\
& \operatorname{SRL}_{i} \times\left(\pi \times D_{\text {root }, i}\right) .
\end{array}\right\}
$$

Where $C_{\text {root }, i}(\mathrm{~g} \mathrm{C} /$ plant) is the fine-root $\mathrm{C}$ density of the PFT $i ; S R L_{i}(\mathrm{~m} / \mathrm{g} \mathrm{C})$ is the specific root length; $D_{\text {root }, i}(\mathrm{~m})$ is the mean diameter of fine roots of PFT $i$. The PFT-specific parameters of $S R L$ and $D_{\text {root }}$ are derived from Jackson et al. (1997). Finally, the actual transpiration rate of the PFT $i\left(\operatorname{Tran}_{i}, \mathrm{~mm} /\right.$ day $)$ and the limitation of water on the plant's GPP $\left(f_{g p p \text {, water, } ; \text {; See }}\right.$ the Appendix) are calculated as:

$$
\left.\begin{array}{l}
\operatorname{Tran}_{i, n}=\operatorname{Pran}_{i, n} \times\left(\operatorname{Tran}_{l c, n} / \operatorname{Ptran}_{l c, n}\right), \\
\operatorname{Tran}_{i}=\sum_{n=1}^{N} \operatorname{Tran}_{i, n}, \\
f_{\text {gpp }, \text { water }, i}=\operatorname{Tran}_{i} / \operatorname{Pran}_{i} .
\end{array}\right\}
$$




\subsection{Modeling root competition for soil inorganic $\mathbf{N}$}

Similar to water uptake, the $\mathrm{N}$ uptake rate (Nup, $\mathrm{g}$ $\mathrm{N} /$ (plant-day)) is linearly proportional to root surface area (i.e. Rtsurf) and the dissolved available soil inorganic $\mathrm{N}(\mathrm{SIN})$ pool size $\left(A V N_{d i s}, \mathrm{~g} \mathrm{~N} / \mathrm{m}^{2}\right)$. It is also a function of soil temperature and plant $\mathrm{N}$ status.

$$
\left.\begin{array}{l}
\operatorname{Nup}_{i}=\eta_{\text {nup }, i} \times k_{T} \times k_{n_{-} \text {defict }} \times \text { Rtsurf }_{i} \times A V N_{\text {dis }}, \\
k_{T}=\frac{\left(T_{\text {soil }}-T_{\max }\right) \times\left(T_{\text {soil }}-T_{\min }\right)}{\left(T_{\text {soil }}-T_{\max }\right) \times\left(T_{\text {soil }}-T_{\min }\right) \times\left(T_{\text {soil }}-T_{\text {opt }}\right) \times\left(T_{\text {soil }}-T_{\text {opt }}\right)}, \\
k_{n_{-} \text {defict }}=1-\exp \left[8.047 \times\left(1-\frac{N_{\text {store }, i}}{N_{\text {store }, i \text { max }}}\right)\right] .
\end{array}\right\}
$$

Where $\eta_{n u p, i}\left(\mathrm{~g} \mathrm{~N} /\left(\mathrm{m}^{2}\right.\right.$-day $\left.)\right)$ is a PFT-specific parameter indicating efficiency of $\mathrm{N}$ uptake; $k_{T}$ is the estimated temperature factor based on the Thornley study (1991), where default values of the temperature parameters $T_{\max }, T_{\min }$, and $T_{\text {opt }}$ are set to 30,25 , and $-5^{\circ} \mathrm{C}$, respectively; $k_{n \_ \text {_efict }}$, plant $\mathrm{N}$ status (i.e. $\mathrm{N}$ deficit), is calculated from the $N_{\text {store }}$ and the maximum $\mathrm{N}$ storage capacity of plant storage organs (see the Appendix). The available soil inorganic $\mathrm{N}(\mathrm{AVN})$ is estimated as:

$$
\left.\begin{array}{l}
A V N=k \text { dif } \times S I N, \\
k_{d i f}=0.9 \times\left(\frac{Q_{\text {soil }}}{F C}\right)^{3}+1 .
\end{array}\right\}
$$

Where $k_{d i f}$ is a factor that accounts for the relative differences in the conductance of the soil to $\mathrm{N}$ diffusion; $Q_{\text {soil }}$ is the water content of soil, and FC is the field capacity. Only a fraction of AVN is dissolved in the soil water (i.e. $A V N_{d i s}$ ), and the rest is adsorbed to soil particle surfaces $\left(A V N_{\text {sorr }}\right)$.

The balance between the two portions of AVN is determined by the Michaelis-Menten kinetics model:

$$
\left.\begin{array}{l}
A V N_{\text {sorb }}=\frac{k_{\max } \times A V N_{d i s}}{k_{0.5}+A V N_{d i s}}, \\
A V N=A V N_{d i s}+A V N_{s o r b} .
\end{array}\right\}
$$

Where $k_{\max }$ is the maximum $A V N$ adhered to the soil, and $k_{0.5}$ is the Michaelis constant. The value of $A V$ $N_{d i s}$ is obtained by solving the above equations.

\subsection{Factors that control the SOM decomposition rate}

Carbon enters the ecosystem through photosynthesis, and exits in the ecosystem as autotrophic respiration, heterotrophic respiration (the decomposition of SOM and PROD pools), and DOC leaching. The structure and parameters of the detritus sub-module in AEM-DV are similar to those of the Terrestrial C Model (for product pools; Houghton et al., 1983) and BIOME-BGC v4.1 (Running and Coughlan 1988; Thornton et al., 2005) with modifications on the scalars that control the decomposition rate (Decom, $\mathrm{g}$ $\left.\mathrm{C} /\left(\mathrm{m}^{2} \cdot \mathrm{day}\right)\right)$.

$$
\left.\begin{array}{l}
\text { Decom }_{d}=k_{d} \times f\left(T_{d}\right) \times f\left(w f p s_{d}\right) \times f(N) \times C_{d}, \\
f\left(w f p s_{d}\right)=3.71 \times w f p s_{d}{ }^{2}-7.48 \times w f p s_{d}+4.13\left(w f p s_{d}>0.6\right), \\
f\left(w f p s_{d}\right)=1 /\left(0.55 \leq w f p s_{d} \leqslant 0.6\right), \\
f\left(w f p s_{d}\right)=1 /\left[1+4 \times \exp \left(-6 \times r w c_{d}\right)\right]\left(w f p s_{d}<0.55\right), \\
r w c d=\left(w f p s_{d}-\frac{W P}{S A T}\right) /\left(0.55-\frac{W P}{S A T}\right), \\
f\left(T_{d}\right)=\exp \left[308.56 \times\left(\frac{1}{71.02}-\frac{1}{T_{d}+46.02}\right)\right], \\
f(N)=0.9+0.1 \times \sqrt{8.5 / C_{-} N_{\text {SOM }, r}} .
\end{array}\right\}
$$

Where $d$ denotes the quality of the detritus $\mathrm{C}$ pool $C_{d}$ $\left(\mathrm{g} / \mathrm{m}^{2}\right)$; the temperature function $f\left(T_{d}\right)$ is based on research by Lloyd and Taylor (1994), where $T_{d}\left({ }^{\circ} \mathrm{C}\right)$ refers to the temperature of the detritus pool; $T_{d}=T_{\text {avg }}$ for the aboveground litter pools, and $T_{d}=T_{\text {soil }}$ for the belowground pools. $w f p s_{d}(0-1)$ is the water-filled porosity of the soil (see Appendix for detail). When $w f p s_{d}>0.6$, soil decomposition is limited by soil oxygen. The effect is modeled with the equation developed by Friend et al. (1997). When $w f p s_{d}<0.55$, 
decomposition is limited by soil water. The effect of water limitation is addressed with the rwc-model approach, as described in Paul (2001). $C_{-} N_{S O M, r}$ is the $\mathrm{C}: \mathrm{N}$ ratio of resistant $\mathrm{SOM}$.

Dynamics of soil inorganic pools is expressed as:

$$
\begin{aligned}
\Delta S I N= & (N d e p+N f i x+N \mathrm{~min})- \\
& \left(N u p+N l e a c h+N_{3}, e m+N x O y_{e m}\right) .
\end{aligned}
$$

Where SIN is composed of $\mathrm{NH}_{\mathrm{x}}$ and $\mathrm{NO}_{\mathrm{y}}$; Ndep, Nfix, and $N \min \left(\mathrm{g} \mathrm{N} / \mathrm{m}^{2} \cdot \mathrm{d}\right)$ are the daily $\mathrm{N}$ deposition rates, fixation rates, and mineralization rates, respectively; Nup, $h, \mathrm{NH}_{3, e m}$, and $N x O y_{e m}\left(\mathrm{~g} \mathrm{~N} / \mathrm{m}^{2} \cdot \mathrm{d}\right)$ are the $\mathrm{N}$ uptake by plants (see below), $\mathrm{N}$ lost through leaching, $\mathrm{NH}_{3}$ emission and trace gas (e.g. $\mathrm{N}_{2} \mathrm{O}, \mathrm{NO}$, and $\mathrm{N}_{2}$ ) emissions, respectively. The annual rate of $\mathrm{NH}_{\mathrm{x}}$ and $\mathrm{NO}_{\mathrm{y}}$ deposition should be provided as inputs. Daily Ndep is calculated as:

$$
\begin{aligned}
N d e p= & \frac{N d e p_{a n n} \times k_{d r y}}{365}+N d e p_{a n n} \times \\
& \left(1-k_{d r y}\right) \times \frac{P p t}{P p t_{a n n}} .
\end{aligned}
$$

Where $\operatorname{Ndep}_{a n n}\left(\mathrm{~g} \mathrm{~N} / \mathrm{m}^{2} \cdot \mathrm{a}\right)$ and $P p t_{a n n}(\mathrm{~mm} / \mathrm{a})$ are the annual $\mathrm{N}$ deposition and precipitation, respectively; $k_{d r y}$ is a parameter that defines the fraction of dry deposition. $\mathrm{k}_{\mathrm{dry}}$ approximates 0.5 according to Lohse et al. (2008). To estimate the $\mathrm{N}$ fixation and leaching rates, AEM-DV adopts the $\mathrm{N}$ fixation module and the $\mathrm{N}$ leach module of the CENTURY model v5.0 (Parton et al., 1988). The $\mathrm{N}$ input through biological fixation is added to the labile litter pool.

High concentrations of dissolved $\mathrm{NH}_{4}^{+}$ions in re- cently fertilized or limed soil may cause the formation of gaseous $\mathrm{NH}_{3}$. AEM-DV assumes $\mathrm{NH}_{3}$ volatilization occurs as soon as gaseous $\mathrm{NH}_{3}$ emerges. $\mathrm{NH}_{3}$ volatilization is a reversible chemical process, which is strongly related to the potential volatilization rate $\left(k_{v o l}\right), \mathrm{pH}$ and $\left[\mathrm{NH}_{4}^{+}\right]$, as shown in Martin and Reddy (1984):

$$
\mathrm{NH}_{3, \mathrm{em}}=k_{\text {vol }} \times 5.8 \times 10^{\mathrm{PH}-10} \times\left[\mathrm{NH}_{x}\right] .
$$

Trace gas emissions take place during nitrification and denitrification (see Appendix for detail). AEM-DV assumes that $\mathrm{NxOy}_{e m}$ is linearly related to the rates of nitrification and denitrification, $N x O y_{e m}=k_{\text {nit }} \times$ nitrification $+k_{\text {den }} \times$ denitrification. (13)

Default values of $k_{n i t}$ and $k_{d e n}$ are 0.001 and 1, respectively (Lin et al., 2000).

\section{Methods}

To evaluate performance of AEM-DV in modeling plant physiologies and biogeochemical processes, we compared the model predictions against measured $\mathrm{C}$ fluxes at three Ameriflux sites with different dryland PFTs: the arid/semiarid grassland in Vaira Ranch, CA $\left(38.41^{\circ} \mathrm{E}, 120.95^{\circ} \mathrm{W}\right)$, the Sevilleta desert shrub in $\mathrm{NM}\left(34.33^{\circ} \mathrm{E}, 106.74^{\circ} \mathrm{W}\right)$, and a typical dryland montane forest in Flagstaff, AZ $\left(35.09^{\circ} \mathrm{E}, 111.76^{\circ} \mathrm{W}\right)$. Detail information about the flux sites are found in Table 2. Physiological parameters for desert shrub, arid/semiarid grassland, and montane forest were collected through literature review, including webpages, and based on experts opinion if other resources are unavailable (Appendix Table A1).

Table 2 Location and description of the Ameriflux sites (Law et al., 2005) that were used for model validation

\begin{tabular}{lllc}
\hline \multicolumn{1}{c}{ PFT } & \multicolumn{1}{c}{ Grass } & Evergreen needleleaf tree & Desert shrub \\
\hline Ameriflux site & Vaira ranch, CA & Flagstaff, AZ & Sevilleta desert shrubland, NM \\
Latitude $\left({ }^{\circ} \mathrm{E}\right)$ & 38.41 & 35.09 & 34.33 \\
Longitude $\left({ }^{\circ} \mathrm{W}\right)$ & -120.95 & -111.76 & -106.74 \\
Elevation $(\mathrm{m})$ & 129 & 2180 & 1593 \\
Time period & $2002-2007$ & 2007 & 2008 \\
Precipitation $(\mathrm{mm} / \mathrm{a})$ & 565 & 636 & 250 \\
Potential evapotranspiration $(\mathrm{mm} / \mathrm{a})$ & 1000 & 1000 & 1400 \\
Soil clay content & 0.13 & 0.295 & 0.09 \\
Soil sand content & 0.3 & 0.335 & 0.64 \\
Soil bulk density $\left(\mathrm{g} / \mathrm{cm}^{3}\right)$ & 1.43 & 1.2 & 1.25 \\
Nhx deposition $\left(\mathrm{g} \mathrm{N} / \mathrm{m}^{2} \cdot \mathrm{a}\right)$ & 0.11 & 0.027 & 0.089 \\
Noy deposition $\left(\mathrm{g} \mathrm{N} / \mathrm{m}^{2} \cdot \mathrm{a}\right)$ & 0.17 & 0.164 & 0.119 \\
\hline
\end{tabular}


To evaluate AEM-DV's capacity in modeling effects of water stress on vegetation dynamic and community structure, i.e. the relative dominance or coverage of different PFTs in a community, we compared the modeled community structures to field observations from a precipitation (and elevation) gradient in the arid region of northwestern China. In August 2010, we conducted a field survey to investigate plant community structure in four dryland sites that distributed along an elevation gradient ranging from 490 to 1,350 $\mathrm{m}$ above sea level, at the northern slope of Tianshan Mountains, northwestern China. Annual precipitation increased while the mean temperature decreased with the altitude, affecting the community structure along the gradient. Based on the Line-Intercept Method (Canfield, 1941), we randomly set up 119 sample lines, each having a length of $50 \mathrm{~m}$ (Table 3 ). In each sample, we measured the distance of first contact to the last contact of a particular PFT according to a tape measure, and the coverage of PFT $i$ is calculated as Cover $_{i}=$ (total distance of PFT i/length of the tape temperature $(50 \mathrm{~m})) \times 100 \%$. We ignored the leaf overlaps of the same PFT and the gaps less than $10 \mathrm{~cm}$ while counted overlap of different PFTs and gaps greater than $10 \mathrm{~cm}$.

We also included a nearby montane forest site (dominated by Picea schrenkiana, an evergreen needleleaf tree) located at $2,173 \mathrm{~m}$ above sea level. The site has been investigated by Luo (1996), who measured vegetation $\mathrm{C}$ density of different PFTs. Detail information of the five study sites was listed in Table 3. The Fukang desert site (site 0 in Table 3 ) with the lowest elevation (490 m) was used for model calibration. Then, the AEM-DV was run to equilibrium state driven by environmental datasets of the other four sites (sites 1-4). Information about the environmental drivers is found in Table 3. We compared the modeled vegetation coverage against field observations for sites $1-3$, and the modeled vegetation $\mathrm{C}$ densities against the values reported by Luo (1996) for site 4 .

To evaluate model capacity in addressing interacttions between the $\mathrm{N}$ and $\mathrm{C}$ processes, we modeled the effects of elevated $\mathrm{N}$ deposition $\left(\mathrm{Ndep}, \mathrm{g} \mathrm{N} / \mathrm{m}^{2} \cdot \mathrm{a}\right)$ on biomass of one desert shrub (Alhagi sparsifolia) and

Table 3 Description of the model inputs for the five sites along a precipitation gradient in northwestern China, which were used to evaluate model performance in simulation community structure and vegetation dynamics.

\begin{tabular}{|c|c|c|c|c|c|c|}
\hline Site ID & 0 & 1 & 2 & 3 & 4 & References and data sources \\
\hline Lat $\left({ }^{\circ} \mathrm{E}\right) / \operatorname{Lon}\left({ }^{\circ} \mathrm{W}\right)$ & $44.3 / 88.1$ & $44.4 / 88.6$ & $44.0 / 88.1$ & $44.0 / 88.1$ & $44.2 / 88.0$ & \multirow{5}{*}{$\begin{array}{l}\text { (National Aeronautics and Space Administration, } \\
\text { 2009) }\end{array}$} \\
\hline Site description & Desert & Desert & $\begin{array}{l}\text { Arid } \\
\text { grassland }\end{array}$ & $\begin{array}{l}\text { Mid-mountain } \\
\text { steppe }\end{array}$ & $\begin{array}{l}\text { Montane } \\
\text { forest }\end{array}$ & \\
\hline Elevation (m) & 490 & 513 & 993 & 1350 & 2173 & \\
\hline Aspect (degree) & 315 & 90 & 106.6 & 51 & 135 & \\
\hline Slope (degree) & 0.11 & 0.16 & 11.95 & 14.49 & 0.56 & \\
\hline $\begin{array}{l}\text { Bulk density } \\
\left(\mathrm{g} / \mathrm{cm}^{3}\right)\end{array}$ & 1.38 & 1.39 & 1.41 & 1.42 & 1.79 & \multirow{6}{*}{ (Nachtergaele et al., 2008) } \\
\hline Clay content $(\%)$ & 21 & 21 & 19 & 19 & 20 & \\
\hline Sand content $(\%)$ & 33 & 35 & 39 & 45 & 50 & \\
\hline Silt content $(\%)$ & 46 & 44 & 42 & 36 & 30 & \\
\hline $\mathrm{pH}$ & 7.8 & 7.8 & 6 & 6.4 & 8.1 & \\
\hline Soil depth (m) & 2.79 & 3.32 & 1 & 1 & 1 & \\
\hline $\mathrm{NHX}\left(\mathrm{g} \mathrm{N} / \mathrm{m}^{2} \cdot \mathrm{a}\right)$ & 0.4 & 0.4 & 0.4 & 0.4 & 0.33 & \multirow{3}{*}{ (Yuan and Wang, 1997) } \\
\hline $\operatorname{NOY}\left(\mathrm{g} \mathrm{N} / \mathrm{m} \cdot{ }^{2} \mathrm{a}\right)$ & 0.2 & 0.2 & 0.2 & 0.2 & 0.37 & \\
\hline $\mathrm{CO}_{2}(\mathrm{ppmv})$ & 389.8 & 389.8 & 389.8 & 389.8 & 389.8 & \\
\hline $\begin{array}{l}\text { Annual precipitation } \\
(\mathrm{mm} / \mathrm{a})\end{array}$ & 180 & 134 & 202 & 350 & 557 & \multirow{4}{*}{$\begin{array}{l}\text { Site 0: Fukang weather station of China Meteoro- } \\
\text { logical Administration. Site 1: climate date measured } \\
\text { by Li et al. (2011). Climate data for site 2-4 were } \\
\text { generated using the microclimate simulator, MT- } \\
\text { CLIM } 4.3 \text { (Thornton and Running, 1999), based on } \\
\text { records from the Tianchi weather station. Tempera- } \\
\text { ture laps rate was calculated based on the difference } \\
\text { between the Tianchi and Fukang stations. }\end{array}$} \\
\hline $\begin{array}{l}\text { Mean daily temperature } \\
\left({ }^{\circ} \mathrm{C}\right)\end{array}$ & 9.5 & 7.9 & 5.3 & 11.9 & 5.1 & \\
\hline Solar radiation $\left(\mathrm{w} / \mathrm{m}^{2}\right)$ & 666 & 347 & 460 & 611.5 & 341.4 & \\
\hline Mean VPD $(\mathrm{Pa})$ & 810 & 1036 & 552 & 1006.3 & 536.3 & \\
\hline Number of samples & 28 & 54 & 27 & 10 & & \\
\hline Measurements & \multicolumn{4}{|c|}{ Coverage (\%) } & \multicolumn{2}{|c|}{$\begin{array}{l}\text { Vegetation C This study } \\
\left(\mathrm{g} \mathrm{C}^{2} \mathrm{~m}^{2}\right)\end{array}$} \\
\hline
\end{tabular}


two arid grass species (Zygophyllum fabago and Plantago maritima), and compared the results against observations from an $\mathrm{N}$ enrichment experiment conducted in the Fukang desert site (site 0 in Table 3) (Zhou, 2008). The background $\mathrm{N}$ deposition in the control study was about $0.8 \mathrm{~g} \mathrm{~N} / \mathrm{m}^{2} \cdot \mathrm{a}$, the two $\mathrm{N}$ treatments increased the $\mathrm{N}$ deposition by $200 \%$ and $400 \%$ (i.e. 1.6 and $3.2 \mathrm{~g} \mathrm{~N} / \mathrm{m}^{2} \cdot \mathrm{a}$ ), respectively. Physiological parameters for grass and shrub are found in Appendix Table A1. Phenological parameters
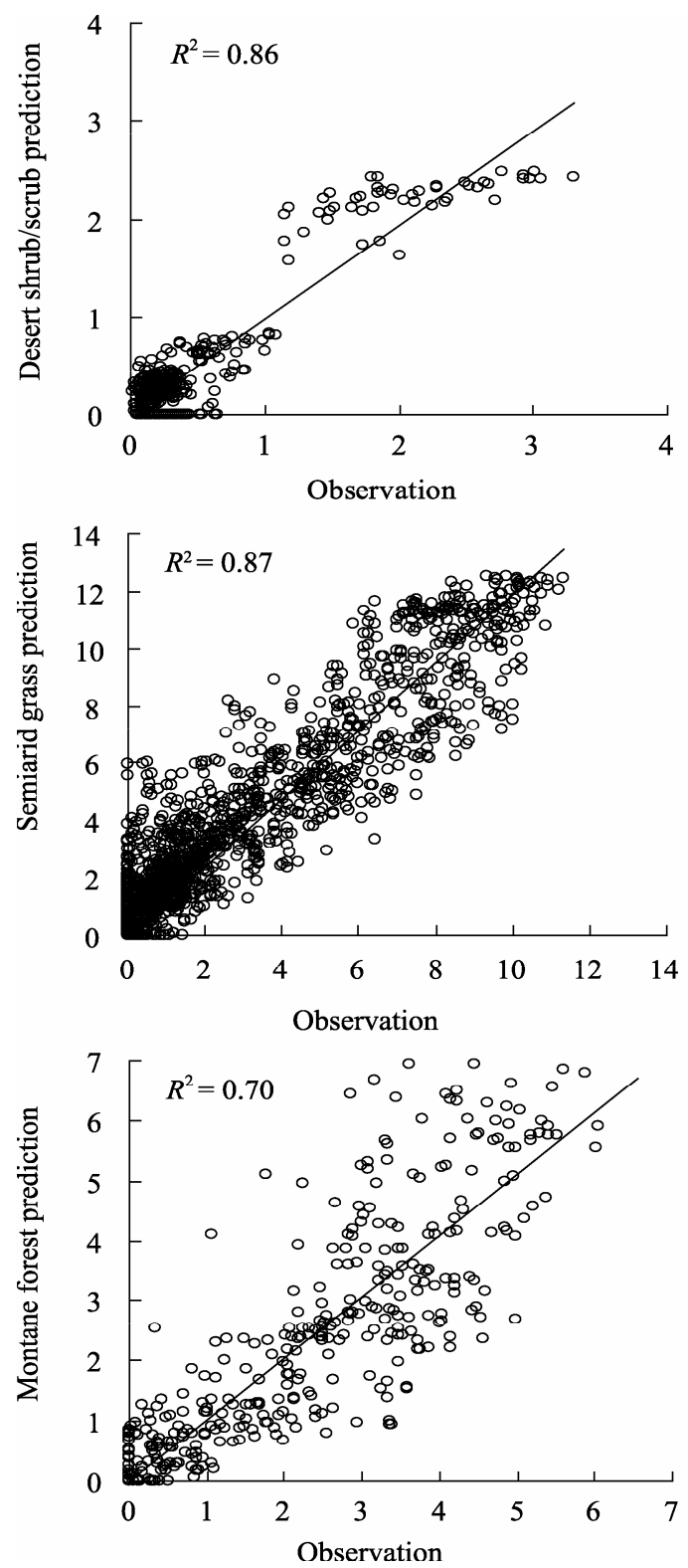

for temperate shrub and grass are shown in Appendix Table A2.

\section{Results and discussion}

The results indicated that model predictions were significantly correlated $(P<0.05)$ to observations from all sites for both gross primary productivity (GPP) and net ecosystem exchanges (NEE) (Fig. 2). The correlation strength (or R-squared values) of GPP was higher
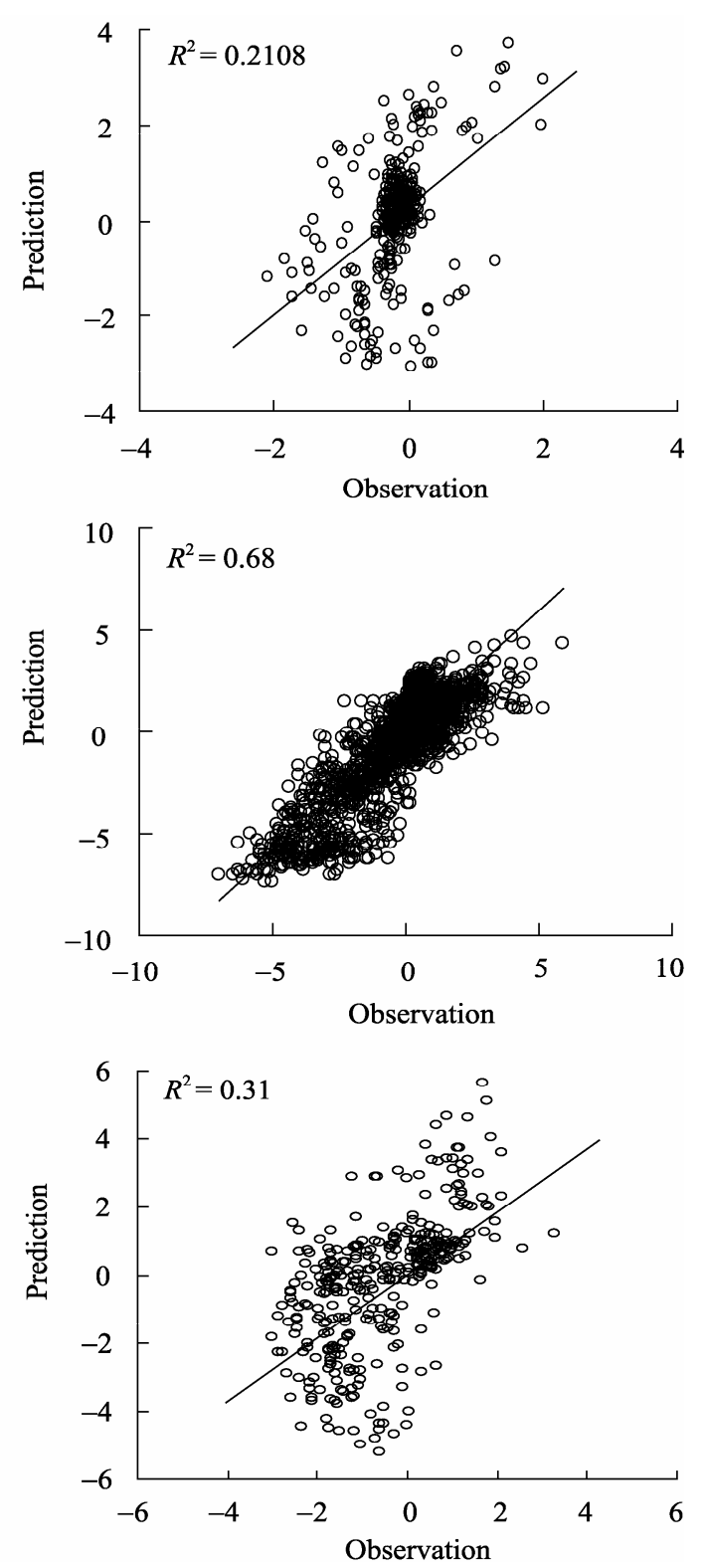

Fig. 2 Comparing model predicted gross primary productivities (GPP; $\mathrm{g} \mathrm{C} / \mathrm{m}^{2} \cdot \mathrm{d}$; Panel A) and net ecosystem exchange rates (NEE; $g$ $\mathrm{C} / \mathrm{m}^{2} \cdot \mathrm{d}$; Panel B) against observed C fluxes in three arid/semiarid Ameriflux sites with different plant functional types. See Table 2 for site descriptions. The $\mathrm{R}^{2}$ values indicate the correlation coefficient between the observations and the model predictions. 
than that of NEE. This indicates that the primary productivity of an ecosystem responds promptly to short-term environmental changes, while NEE is also controlled by ecosystem respiration rates, which are related to the long-term dynamics of vegetation biomass and soil $\mathrm{C}$ storage. Because historical climate and atmospheric data were unavailable for the Ameriflux sites, the long-term environmental changes of the validation sites were unable to be replicated. Nevertheless, the significant correlations between model predictions and observations indicated AEM-DV modeled the physiologies and biogeochemical processes in the three arid or semiarid ecosystems reasonably.

The results showed that AEM-DV could predict the changes in vegetation coverage along the precipitation gradient on the northern slope of the Tianshan Moun- tains accurately (Fig. 3). Although the model seemed to overestimate the vegetation coverage of the mid-mountain steppe (site 3), while underestimating the vegetation coverage of the arid grassland (site 2), the predicted values still fell within one standard error of field observations. More importantly, the simulation showed that AEM-DV predicted the relative dominance of grass, shrubs, and trees in different sites along the precipitation gradient (Fig. 3), indicating that the model could capture climate change impacts on ecosystem structures and vegetation dynamics in dryland. Due to the limitation of field information, only the climate effect was investigated. The $\mathrm{N}$ enrichment experiments also showed that the AEM-DV is capable to model the effects of $\mathrm{N}$ process on the $\mathrm{C}$ cycle (Fig. 4). The model, however, seems to overestimate the vegetation sensitivity to the $\mathrm{N}$ enrichments.

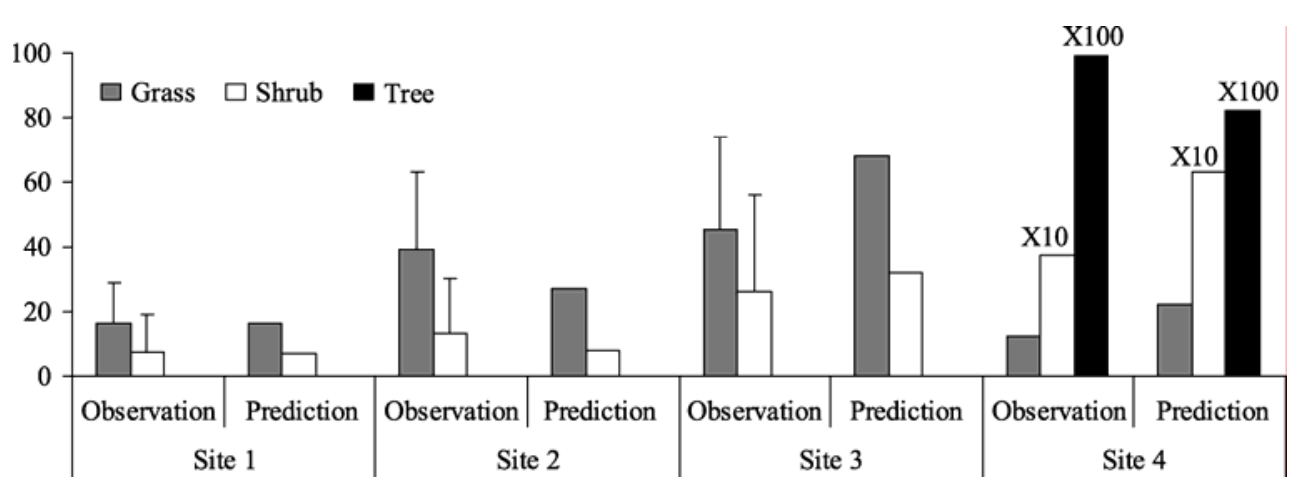

Fig. 3 Comparing model predicted PFT coverage (unit: 0-100; for sites 1-3) and vegetation C densities (10g C/m $\mathrm{m}^{2}$ for grass and shrub, and $100 \mathrm{~g} \mathrm{C} / \mathrm{m}^{2}$ for tree; for site 4) against field observations from four dryland ecosystems along a precipitation gradient at the northern slope of the Tianshan Mountains, northwestern China. Sites information is shown in Table 4. The error bars indicate one standard error.

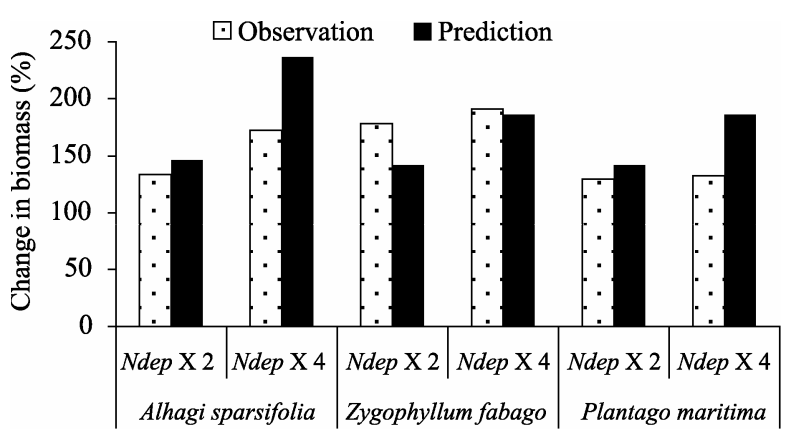

Fig. 4 Comparing the model predicted and observed (Zhou, 2008) biomass changes in response to $\mathrm{N}$ enrichment for a desert shrub (Alhagi sparsifolia) and two arid grasses (Zygophyllum fabago and Plantago maritima). Ndep is the background $\mathrm{N}$ deposition rate in the Fukang desert site $=0.8 \mathrm{~g} \mathrm{~N} / \mathrm{m}^{2} \cdot \mathrm{a}$.
Notwithstanding, this study indicated that by explicitly modeling the ecological and biogeochemical processes, such as resource competition, plant structure, and complex interactions among the energy, water, $\mathrm{C}$, and $\mathrm{N}$ processes, AEM-DV was capable to simulate vegetation dynamic and its effect on biogeochemical cycles of dryland ecosystems in response to multiple controls.

Since the industrial revolution, the global climate and atmospheric systems have undergone rapid changes, largely due to anthropogenic disturbances. These changes could have profound effects on the structure and functions of stressed ecosystems like 
those in dryland. Despite their enormous coverage areas, however, dryland ecosystems were not the focus of most global climate change studies, a fact manifested in the absence of models designed for regional or global dryland studies.

For the global dynamic vegetation models currently in use, the sensitivity of the dryland vegetation community to climate changes was seldom considered. The widely used LPJ model (Sitch et al., 2003), for example, overlooks the effects of long-term precipitation on the vegetation dynamic of PFTs. Many important soil processes in dryland ecosystems, such as root competition for soil water and the effects of soil water stress on organic matter decomposition, as well as the strong influence of canopy structure on the energy and water partitions, are also either overlooked or oversimplified in most models. Many models do not include the $\mathrm{N}$ cycle or decouple it from $\mathrm{C}$ and water cycles, and therefore, may overlook the effects of $\mathrm{N}$ limitation on ecosystem productivity (Krinner et al., 2005), and are unable to estimate the trace gas emissions such as the $\mathrm{NO}$ and $\mathrm{N}_{2} \mathrm{O}$ pulses from desert soil in response to abrupt precipitations (Hall et al., 2008; Shen et al., 2009). These problems and limitations have been addressed by the AEM-DV model. Future improvements will include consideration of horizontal water exchanges by coupling the AEM-DV biogeochemical cycles to a two-dimensional hydrological model, such as the Hydrus model (Šimůnek et al., 1999).

\section{Conclusions}

The AEM-DV model addresses several ecological processes that are important to the community structure and vegetation dynamics as well as biogeochemical cycles of the dryland ecosystems, which were largely overlooked by most ecosystem models. These processes include the interactions between $\mathrm{C}$, water, and $\mathrm{N}$ cycles, the root competition for soil $\mathrm{N}$ and water, and the water compensation effect on root water uptake. The effect of precipitation on plant distribution and water stress on soil organic matter decomposition are also considered. Model validations showed that the AEM-DV could capture the impacts of climate and nitrogen factors on the biomass, carbon fluxes, and community structure of several arid ecosystems in China and the United States of America. The model, therefore, provided a useful tool in studying the impacts of environmental changes on the carbon, water, and nitrogen dynamics in the dryland ecosystems.

\section{Acknowledgements}

This study was financially supported by the International Science \& Technology Cooperation Program of China (2010 DFA92720-10), and the "Hundred Talents Program" of the Chinese Academy of Sciences (Y174131001). The study was also supported by the National Basic Research Program of China (2009CB825105).

\section{References}

Ackerman T L. 1979. Germination and survival of perennial plant species in the Mojave Desert. The Southwestern Naturalist, 24: 399-408.

Aguiar M R, Sala O E. 1999. Patch structure, dynamics and implications for the functioning of arid ecosystems. Trends in Ecology \& Evolution, 14: 273-277.

Allen-Diaz B, Chapin F S, Diaz S, et al. 1996. Rangelands in a changing climate: impacts, adaptations and mitigation. In: Watson $\mathrm{R} \mathrm{T}$, Zinyowera M C, Moss R H, et al. Climate Change 1995 Impacts, Adaptation and Mitigation, Contribution of Working Group II to the Second Assessment Report of the Intergovernmental Panel on Climate Change. Cambridge: Cambridge University Press, 131-158.

Austin A T, Yahdjian L, Stark J M, et al. 2004. Water pulses and biogeochemical cycles in arid and semiarid ecosystems. Oecologia, 141: 221-235.

Braswell B H, Schimel D S, Linder E, et al. 1997. The response of global terrestrial ecosystems to interannual temperature variability. Science, 278: 870-873.

Canfield R H. 1941. Application of the line interception method in sampling range vegetation. Journal of Forestry, 39: 388-394.

Chiba Y. 1990. Plant form analysis based on the pipe model theory I. A statical model within the crown. Ecological Research, 5: 207-220.

Cook E R, Woodhouse C A, Eakin C M, et al. 2004. Long-term aridity changes in the western United States. Science, 306: 1015-1018.

Drake B G, Gonzàlez-Meler M A, Long S P. 1997. More efficient plants: a consequence of rising atmospheric $\mathrm{CO}_{2}$ ? Annual Review of Plant Physiology and Plant Molecular Biology, 48: 609-639.

Ehlers W, Hamblin A P, Tennant D, et al. 1991. Root system parameters determining water uptake of field crops. Irrigation Science, 12: 115-124. 
English M, Raja S N. 1996. Perspectives on deficit irrigation. Agricultural Water Management, 32: 1-14.

Feddes R A, Raats P A C. 2004. Parameterizing the soil-water-plant root system. In: Feddes R A, de Rooij G H, Van Dam J C. Proceedings of the Unsaturated Zone Modeling: Progress, Challenges and Applications. Dordrecht: Kluwer Academic Publishers, 95-141.

Foley J A, Prentice I C, Ramankutty N, et al. 1996. An integrated biosphere model of land surface processes, terrestrial $\mathrm{C}$ balance, and vegetation dynamics. Global Biogeochemical Cycles, 10: 603-628.

Friend A D, Stevens A K, Knox R G, et al. 1997. A process-based, terrestrial biosphere model of ecosystem dynamics (Hybrid v3.0). Ecological Modeling, 95: 249-287.

Gale M R, Grigal D F. 1987. Vertical root distributions of northern tree species in relation to successional status. Canadian Journal of Forest Research, 17: 829-834.

Gutierrez J R, Whitford W G. 1987. Chihuahuan desert annuals: importance of water and nitrogen. Ecology, 68: 2032-2045.

Hall S J, Huber D, Grimm N B. 2008. Soil $\mathrm{N}_{2} \mathrm{O}$ and $\mathrm{NO}$ emissions from an arid, urban ecosystem. Journal of Geophysical Research, 113, G01016, doi: 10.1029/2007JG000523.

Hasegawa S, Yoshida S. 1982. Water uptake by dryland rice root system during soil drying cycle. Soil Science and Plant Nutrition, 28: 191-204.

Haxeltine A, Prentice I C. 1996. BIOME3: an equilibrium terrestrial biosphere model based on ecophysiological constraints, resource availability, and competition among plant functional types. Global Biogeochemical Cycles, 10: 693-709.

Houghton R A, Hobbie J E, Melillo J M, et al. 1983. Changes in the C content of terrestrial biota and soils between 1860 and 1980: a net release of $\mathrm{CO}_{2}$ to the atmosphere. Ecological Monographs, 53: 235-262.

Ingle J D J, Crouch S R. 1988. Spectrochemical Analysis. New Jersey: Prentice Hall.

IPCC. 2012. Managing the risks of extreme events and disasters to advance climate change adaptation. In: Field C B, Barros V, Stocker T F, et al. A Special Report of Working Groups I and II of the Intergovernmental Panel on Climate Change. Cambridge and New York: Cambridge University Press, 582.

Jackson R B, Mooney H A, Schulze E D A. 1997. A global budget for fine root biomass, surface area, and nutrient contents. Proceedings of the National Academy of Sciences of the United States of America, 94: 7362-7366.

Keeling C D, Piper S C, Bacastow R B, et al. 2001. Exchanges of atmospheric $\mathrm{CO}^{2}$ and ${ }^{13} \mathrm{CO}_{2}$ with the terrestrial biosphere and oceans from 1978 to 2000. I. Global aspects. In: Ehleringer J R, Cerling T E, Dearing M D. Scripps Institution of Oceanography Reference No. 01-06. UC San Diego: Scripps Institution of Oceanography, 1-28.

Kemp P R, Reynolds J F, Pachepsky Y, et al. 1997. A comparative modeling study of soil water dynamics in a desert ecosystem. Water Resources Research, 33: 73-90.
Krinner G, Viovy N, de Noblet-Ducoudré N, et al. 2005. A dynamic global vegetation model for studies of the coupled atmosphere-biosphere system. Global Biogeochemical Cycles, 19, GB1015, doi: 10.1029/2003GB002199.

Ladwig L M, Collins S L, Swann A L, et al. 2012. Above- and belowground responses to nitrogen addition in a Chihuahuan Desert grassland. Oecologia, 169: 177-185.

Lal R. 2001. Potential of desertification control to sequester carbon and mitigate the greenhouse effect. Climatic Change, 51: 35-72.

Law B E, Loescher H W, Boden T A, et al. 2005. Ameriflux Site Evaluation and Recommendations for Network Enhancement. Oak Ridge: Oak Ridge National Laboratory. [2012-3-21]. http://public.ornl.gov/ameriflux.

Leib B G, Caspari H W, Redulla C A, et al. 2006. Partial rootzone drying and deficit irrigation of 'Fuji' apples in a semi-arid climate. Irrigation Science, 24: 85-99.

Li L H, Luo G P, Chen X, et al. 2011. Modelling evapotranspiration in a Central Asian desert ecosystem. Ecological Modelling, 222: 3680-3691.

Lin B L, Sakoda A, Shibasaki R, et al. 2000. Modeling a global biogeochemical nitrogen cycle in terrestrial ecosystems. Ecological Modelling, 135: 89-110.

Lohse K A, Hope D, Sponseller R A, et al. 2008. Atmospheric deposition of nutrients across a desert city. Science of the Total Environment, 402: 95-105.

Luo T X. 1996. Patterns of net primary productivity for Chinese major forest types and their mathematical models. PhD Dissertation. Beijing: Chinese Academy of Sciences.

Manabe S, Broccoli A J. 1990. Mountains and arid climates of middle latitudes. Science, 247: 192-194.

Martin J F, Reddy K R. 1984. Interaction and spatial distribution of wetland nitrogen processes. Ecological Modelling, 105: 1-21.

Montaño N M, García-Oliva F, Jaramillo V J. 2007. Dissolved organic carbon affects soil microbial activity and nitrogen dynamics in a Mexican tropical deciduous forest. Plant and Soil, 295: 265-277.

Nachtergaele F, van Velthuizen H, Verelst L. 2008. Harmonized World Soil Database. Rome: Food and Agriculture Organization of the United Nations and Laxenburg: International Institute for Applied Systems Analysis.

National Aeronautics and Space Administration. 2008. ASTER Global DEM. Washington DC: National Aeronautics and Space Administration. [2012-3-21]. http://gdex.cr.usgs.gov/gdex/.

Notaro M. 2008. Response of the mean global vegetation distribution to interannual climate variability. Climate Dynamics, 30: 845-854.

Parton W J, Stewart J W B, Cole C V. 1988. Dynamics of C, N, P and S in grassland soils: a model. Biogeochemistry, 5: 109-131.

Passioura J B. 1985. Roots and water economy of wheat. In: Day W, Atkin R K. Wheat Growth and Modelling. New York: Plenum Press, 407.

Quevedo D I, Frances F. 2008. A conceptual dynamic vegetation-soil 
model for arid and semiarid zones. Hydrology and Earth System Sciences, 12: 1175-1187.

Reynolds J F, Kemp P R, Tenhunen J D. 2000. Effects of long-term rainfall variability on evapotranspiration and soil water distribution in the Chihuahuan Desert: a modeling analysis. Plant Ecology, 150: 145-159.

Reynolds J F, Smith D M S, Lambin E F, et al. 2007. Global desertification: building a science for dryland development. Science, 316: 847-851.

Rotenberg E, Yakir D. 2010. Contribution of semi-arid forests to the climate system. Science, 327: 451-454.

Running S W, Coughlan J C. 1988. A general model of forest ecosystem processes for regional applications I. Hydrologic balance, canopy gas exchange and primary production processes. Ecological Modeling, 42: 125-154.

Scheffer M, Carpenter S, Foley J A, et al. 2001. Catastrophic shifts in ecosystems. Nature, 413: 591-596.

Schimel J P, Weintraub M N. 2003. The implications of exoenzyme activity on microbial carbon and nitrogen limitation in soil: a theoretical model. Soil Biology and Biochemistry, 35: 549-563.

Shao P, Zeng X D. 2011. The impact of interannual climate variability on the mean global vegetation distribution. Acta Ecologica Sinica, 31(6): 1494-1505.

Shaw M R, Zavaleta E S, Chiariello N R, et al. 2002. Grassland responses to global environmental changes suppressed by elevated $\mathrm{CO}_{2}$. Science, 298: 1987-1990.

Shen W J, Wu J G, Kemp P R, et al. 2005. Simulating the dynamics of primary productivity of a Sonoran ecosystem: model parameterization and validation. Ecological Modelling, 189: 1-24.

Shen W J, Reynolds J F, Hui D F. 2009. Responses of dryland soil respiration and soil carbon pool size to abrupt vs. gradual and individual vs. combined changes in soil temperature, precipitation, and atmospheric $\mathrm{CO}_{2}$ : a simulation analysis. Global Change Biology, 15: 2274-2294.

Shinozaki K, Yoda K, Hozumi K, et al. 1964. A quantitative analysis of plant form - the pipe model theory: I. basic analyses. Japanese Journal of Ecology, 14: 97-105.

Šimůnek J, Šejna J, van Genuchten M Th. 1999. The Hydrus-2D Software Package for Simulating Two-dimensional Movement of Water, Heat, and Multiple Solutes in Variably Saturated Media. Version 2.0, IGWMC-TPS-53. Colorado: International Ground Water Modeling Center, Colorado School of Mines, 1-251.

Sitch S, Smith B, Prentice I C, et al. 2003. Evaluation of ecosystem dynamics, plant geography and terrestrial carbon cycling in the LPJ dynamic global vegetation model. Global Change Biology, 9: 161-185.

Smith S D, Huxman T E, Zitzer S F, et al. 2000. Elevated $\mathrm{CO}_{2}$ increases productivity and invasive species success in an arid ecosystem. Nature, 408: 79-82.

Sorg A, Bolch T, Stoffel M, et al. 2012. Climate change impacts on glaciers and runoff in Tien Shan (Central Asia). Nature Climate Change, 2: 725-731.

Stikic R, Popovic S, Srdic M, et al. 2003. Partial root drying (PRD): a new technique for growing plants that saves water and improves the quality of fruit. Bulgarian Journal of Plant Physiology, 29: 164-171.

Taylor H M, Klepper B. 1978. The role of rooting characteristics in the supply of water to plants. Advances in Agronomy, 30: 99-128.

Thornley J H M. 1991. A transport-resistance model of forest growth and partitioning. Annals of Botany, 68: 211-226.

Thornton P E, Running S W. 1999. An improved algorithm for estimating incident daily solar radiation from measurements of temperature, humidity, and precipitation. Agricultural and Forest Meteorology, 93: 211-228.

Thornton P E, Running S W, Hunt E R. 2005. Biome-BGC: Terrestrial Ecosystem Process Model, Version 4.1.1. Data Model [Internet]. Oak Ridge: Oak Ridge National Laboratory Distributed Active Archive Center. [2012-6-8]. http://daac.ornl.gov/cgibin/dsviewer.pl?ds_id=805.

Tian H Q, Melillo J, Lu C Q, et al. 2011. China's terrestrial carbon balance: contributions from multiple global change factors. Global Biogeochemical Cycles, 25, GB1007, doi: 10.1029/2010GB003838.

van der Ploeg R R, Beese F, Strebel O, et al. 1978. The water balance of a sugar beet crop: a model and some experimental evidence. Journal of Plant Nutrition and Soil Science, 141: 313-328.

Vasek F C. 1980. Creosote Bush: Long-lived clones in the Mojave Desert. American Journal of Botany, 67: 246-255.

Walker B H, Langridge J L. 1996. Modelling plant and soil water dynamics in semi-arid ecosystems with limited site data. Ecological Modelling, 87: 153-167.

Wohlfahrt G, Fenstermaker L F, Arnone J A. 2008. Large annual net ecosystem $\mathrm{CO}_{2}$ uptake of a Mojave Desert ecosystem. Global Change Biology, 14: 1475-1487.

Xu G Q, Wei W S. 2004. Climate change of Xinjiang and its impact on eco-enviroment. Arid Land Geogrophy, 27(1): 14-18.

$\mathrm{Xu} \mathrm{H}, \mathrm{Li} \mathrm{Y,Xu} \mathrm{G} \mathrm{Q,} \mathrm{et} \mathrm{al.} \mathrm{2007.} \mathrm{Ecophysiological} \mathrm{response} \mathrm{and}$ morphological adjustment of two Central Asian desert shrubs towards variation in summer precipitation. Plant, Cell \& Environment, 30: 399-409.

Yang R Q, Friedl M A, Ni W G. 2001. Parameterization of shortwave radiation fluxes for nonuniform vegetation canopies in land surface models. Journal of Geophysical Research, 106: 14275-14286.

Yuan X M, Wang Z Q. 1997. Studies on the $\mathrm{NO}_{3}^{-}-\mathrm{N}$ in the environment and soil. Arid Zone Research, 14(4): 52-55.

Zhou X B. 2008. Responses of herbaceous plant growth and microbial activities to simulated nitrogen deposition in Gurbantunggut Desert. $\mathrm{PhD}$ Dissertation. Urumqi: Xinjiang Institute of Ecology and Geography, Chinese Academy of Sciences, 157. 


\section{Appendix}

\section{Estimating biophysical parameters and climate variables}

The AEM-DV is driven by environmental factors such as the daily meteorological factors (minimum, mean, and maximum temperature, precipitation, solar radiation, and vapor pressure deficit), annual $\mathrm{CO}_{2}$ concentration and nitrogen deposition rate. The model estimates several important variables such as daylength (dayl, s), daytime and nighttime air temperature (Tday and Tnight, ${ }^{\circ} \mathrm{C}$ ), soil temperature $\left(\right.$ Tsoil,${ }^{\circ} \mathrm{C}$ ), air pressure (Pressure, Pa), air density $\left(\rho, \mathrm{kg} / \mathrm{m}^{3}\right)$, daily snow $\left(\mathrm{Ppt}_{\mathrm{s}}, \mathrm{mm} /\right.$ day) and rain $\left(\mathrm{Ppt}_{\mathrm{r}}, \mathrm{mm} /\right.$ day), soil water hold capacity (wilting point, WP, and field capacity, FC), which are required by the water, carbon cycling and other submodels. AEM-DV requires information about daily mean vapor pressure deficit (VPD, Pa). It can calculate the value of VPD from the relative humidity (Rhum, \%) or the dew point temperature (Tdew, ${ }^{\circ} \mathrm{C}$ ). If none of this information (VPD, Rhum, and Tdew) is available, AEM-DV can estimate the daily average vapor pressure deficit value from the daily incident solar radiation (inRad, $\mathrm{W} / \mathrm{m}^{2}$ ) and average temperature. If inRad is not available, AEM-DV can estimate it using the algorithms developed by Thornton et al. (1997) and Thornton and Running (1999).

\subsection{Estimation of daylength}

$$
\text { dayl }=2 a \cos ((\sin (L) \sin (D)) / \cos (L) \cos (D)) \times S E C P E R R A D .
$$

Where $L$ denotes latitude; SECPERRAD (=13750.9871) is a constant representing seconds per radian of hourly angle; $D$ denotes declination of the sun:

$$
D=M I N D E C I \times \cos \left(\left(Y_{d a y}+D A Y S O F F\right) \times R A D P E R D A Y\right) .
$$

Where $Y_{\text {day }}$ is the day of the year; MINDECL, DAYSOFF, and RADPERDAY represent minimum declination $(=0.4092797$ radians), year day offset of winter solstice $(=11.25)$, and radians of Earth orbit per day $(=0.017214)$, respectively.

\subsection{Estimation of the daytime, night, and soil temperatures}

$$
\begin{gathered}
T_{d a y}=0.212 \times\left(T_{\max }-T_{a v g}\right)+T_{a v g}, \\
T_{\text {night }}=\left(T_{\text {day }}+T_{\min }\right) / 2.0, \\
T_{\text {soil }}=\sum_{i=1}^{11} T_{i, a v g} / 11.0 .
\end{gathered}
$$

Where $T_{\max }, T_{\text {avg }}$, and $T_{\min }$ are daily maximum, average, and minimum air temperature, respectively. If $T_{\text {avg }}$ is not available from input datasets, it will be approximated as the mean of $T_{\max }$ and $T_{\min }$. Soil temperature is approximated using the mean daily air temperature of the last 11 days.

\subsection{Air pressure and air density}

$$
\text { Pressure }=P_{-} S T D \times\left(1.0-\left(L R_{-} S T D \times e l e v\right) / T_{-} S T D\right)^{G+S T D /\left[L R_{-} S T D \times(R / M A)\right]} .
$$

Where $P \_S T D(=101325 \mathrm{~Pa})$ is standard air pressure at 0 meter of sea level, $L R \_S T D(=0.0065-\mathrm{K} / \mathrm{m})$ is standard temperature lapse rate; elev is elevation $(\mathrm{m}) ; T_{-} S T D(=288.15 \mathrm{~K})$ is standard temperature with elevation of 0 meter. $G \_S T D\left(=9.80665 \mathrm{~m} / \mathrm{s}^{2}\right)$ is standard gravitational acceleration constant; $R\left(=8.3143 \mathrm{~m}^{3} \cdot \mathrm{Pa} /(\mathrm{mol} \cdot \mathrm{K})\right)$ is gas law constant; $M A\left(=28.9644 \mathrm{E}^{-3} \mathrm{~kg} / \mathrm{mol}\right)$ is molecular weight of air. Air density is calculated as:

$$
\rho=1.292-\left(0.00428 \times T_{\text {avg }}\right) \text {. }
$$

\subsection{Partition of precipitation between rain and snow}

Following Wigmosta et al. (1994) AEM-DV allocates daily precipitation into rain and snow according to daily average air temperature (United States Army Corps of Engineers, 1956; Wigmosta et al., 1994): 


$$
\left.\begin{array}{rl}
\text { Ppts } & =P p t \quad T_{a v g} \leq T_{s}, \\
P p t_{s} & =\frac{T_{r}-T_{a v g}}{T_{r}-T_{s}} \quad T_{s}<T_{a v g}<T_{r}, \\
P p t_{s} & =0 \quad T_{a v g} \geq T_{r}, \\
\text { Ppt } & =P p t-P p t_{s} .
\end{array}\right\}
$$

Where $P p t_{r}$ and $P p t_{\mathrm{s}}$ are the water equivalent depths of rain and snow, respectively; $T_{s}\left(=-1.1^{\circ} \mathrm{C}\right)$ is a threshold temperature below which all $\mathrm{Ppt}$ is in the form of snow, and $T_{r}\left(=3.3^{\circ} \mathrm{C}\right)$ is a threshold temperature above which all Ppt is rain (Wigmosta et al., 1994).

\subsection{Estimating the soil water characteristics based on the soil texture and the OM content}

According to the study of Saxton and Rawls (2006), the soil water characteristics such as the volumetric water contents $(0-1)$ of wilt point (when soil water tension=1,500 kPa) (WP), field capacity (when soil water tension=33 $\mathrm{kPa}$ ( $\mathrm{FC}$ ), and saturated moisture (SAT), are estimated based on the values of the soil texture and the soil organic mattern content:

$$
\begin{gathered}
W P=Q_{1500 t}+0.14 \times Q_{1500 t}-0.02, \\
F C=Q_{33 t}+1.283 \times Q_{33 t}{ }^{2}-0.374 \times Q_{33 t}-0.015, \\
S A T=F C+Q_{s_{-} 33}-0.097 \times s+0.043 .
\end{gathered}
$$

While:

$$
\begin{aligned}
& Q_{1500 t}=-0.024 \times s+0.487 \times c+0.006 \times \mathrm{om}+0.005 \times s \times \mathrm{om}-0.013 \times c \times o m+0.068 \times s \times c+0.31, \\
& Q_{33 t}=-0.251 \times s+0.195 \times c+0.011 \times \mathrm{om}+0.006 \times s \times \mathrm{om}-0.027 \times c \times o m+0.452 \times s \times c+0.299, \\
& Q_{s_{-} 33 t}=0.278 \times s+0.034 \times c+0.022 \times \mathrm{om}-0.018 \times s \times \mathrm{om}-0.027 \times c \times o m-0.584 \times s \times c+0.078, \\
& Q_{s_{-} 33}=Q_{s_{-} 33 t}+0.636 \times Q_{s_{-} 33 t}-0.107 .
\end{aligned}
$$

Where $s, c$, and $o m$ are the content of sand, clay, and organic matter $(0-1)$ in the soil respectively. $\theta_{1500 t}, \theta_{33 t}, \theta_{s 33 t}$, and $\theta_{s 33}$ are intermediate variables.

If the value of soil bulk density ( $\mathrm{bd}, \mathrm{g} / \mathrm{m}^{3}$ ) is not available from user input, it will be estimated by AEM-DV using the following empirical equation:

$$
b d=(1.0-S A T) \times 2.65 .
$$

\subsection{Estimating the VPD and inRad}

If information of $V P D$ is available, it can be calculated as

$$
V P D=P v_{s}-P v_{a} .
$$

Where $P v_{s}$ and $P v_{a}(\mathrm{~Pa})$ are saturated vapor pressure and the actual vapor pressure respectively. Using the saturation vapor pressure equations recommended by the World Meteorological Organization (2008), $P v_{s}$ and $P v_{a}$ are calculated from $T_{\text {avg }}$ and $T_{\text {dew }}$, respectively. If Rhum is available from input datasets, $P v a$ can also be calculated as $P v_{a}=P v_{s} \times$ Rhum.

When inRad is not provided by user, the information of humidity (i.e. VPD, Rhum, or Tdew), temperature, and precipitation can be used to estimate the value of inRad (Thornton and Running, 1999). Even if input datasets of humidity are not available, AEM-DV can still use the approaches developed by Thornton et al. (1997) to estimate the value of VPD and inRad.

1.7 Calculating the slope (s) of saturated vapor pressure-temperature curve for the Penman-Monteith equation (Wigmosta et al., 1994)

$$
s=\left(P v_{s, T 1}-P v_{s, T 2}\right) /\left(T_{1}-T_{2}\right)
$$

Where $T_{l}=T_{\text {avg }}+0.2 ; T_{2}=T_{\text {avg }}-0.2 ; P v_{s, T l}$ and $P v_{s, T 2}$ are saturated vapor pressure at $T_{l}$ and $T_{2}$, respectively. 
1.8 Estimating daily $\mathrm{N}$ deposition rate $\left(\mathrm{Ndep}, \mathrm{g} \mathrm{N} / \mathrm{m}^{2}\right)$ from the annual total $\mathrm{N}$ deposition $\left(A N d e p, \mathrm{gN} / \mathrm{m}^{2} \cdot a\right)$

$$
N d e p=f_{\text {wet }} \times A N d e p \times P p t / A p p t+\left[\left(1-f_{\text {wet }}\right) \times A N d e p / 365\right] .
$$

Where Appt $(\mathrm{mm} / \mathrm{a})$ is the accumulated annual precipitation; $f_{\text {wet }}$ is the fraction of wet deposition in the total $\mathrm{N}$ deposition. The default value of $f_{\text {wet }}$ was set to 0.22 (Baker et al., 2001; Lohse et al., 2008).

\section{The hydrological processes and energy partition}

Daily precipitation is intercepted sequentially by the overstory and understory. There are two intercepted water pools in each canopy, i.e. the intercepted water pool $\left(W_{c \text {,water, }} \mathrm{mm}\right)$ and the intercepted water-equivalent snow pool $\left(W_{c, \text { snow }}, \mathrm{mm}\right)$. Throughfall and irrigation water enter the soil and move along the water pressure gradient in the multiple soil layers. During the process, driven by solar energy absorbed by the canopies and the soil surface, water may be lost from the ecosystem through a series of energy-exchange processes: sublimation (of snow), evaporation, and transpiration. The energy exchanges and evapotranspiration rate are estimated using the Penman-Monteith approach (Wigmosta et al., 1994). Finally, a portion of the input water will leave the ecosystem as either surface runoff or drainage flow. Calculations of daily water balances in canopy and soil layers are similar to most ecosystem and land surface models, such as BIOME-BGC (Coughlan and Running, 1988) and PALS (Kemp et al., 1997).

\subsection{Estimating the fraction of ground covered by snow $\left(f_{\text {snow }}\right)$}

The coverage of sonw is estimated from the thickness of the snowpack using the empirical equation of Bonan (1996):

$$
f_{\text {snow }}=\text { Thick }_{\text {snow }} / 0.05 \text {, }
$$

where Thick $_{\text {snow }}(\mathrm{m})$ is the thickness of the snow pack, calculated as:

$$
\text { Thick }_{\text {snow }}=W_{\text {soil,snow }} / \text { Density }_{\text {snow }} \text {. }
$$

Where Density snow $\left(250 \mathrm{~kg} / \mathrm{m}^{3}\right)$ is the density of snow pack.

\subsection{Calculating volumetric water content $(\theta)$ and its soil tension $(\psi)$}

$$
Q_{n}=W_{\text {soil }, n} /\left(S A T \times \text { Thickness }_{n}\right),
$$

where $Q_{n}(0-1)$ is the volumetric water content of soil layer $n$; Thickness $n(\mathrm{~mm})$ is the thickness of the soil layer;

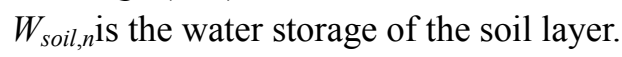

Soil water tension $(\psi)$ can be calculated from its volumetric water content $(\theta, 0-1)$ using the following equation:

$$
\left.\begin{array}{l}
\left.\psi=A /\left(Q^{B}\right) \quad \text { (if } Q \leq F C\right), \\
\psi=33-\left[(Q-F C) \times\left(33-\psi_{e}\right) /(S A T-F C)\right](\text { if } Q>F C), \\
B=[\ln (1500)-\ln (33)] /[\ln (F C)-\ln (W P)], \\
A=e^{\ln (33)+B \times \ln (F C)} .
\end{array}\right\}
$$

\subsection{Calculating soil moisture and water filled porosity (wfps)}

The available soil water $\left(A V W_{n}, \mathrm{~mm}\right)$, the maximum water hold capacity $\left(A V W_{n, \max }, \mathrm{mm}\right)$, and the relative soil moisture $\left(\right.$ moist $\left._{n}\right)$ for a soil layer are calculated as:

$$
\begin{gathered}
A V W_{\text {soil }, n}=\left(Q_{n}-W P\right) \times \text { Thickness }_{n}, \\
A V W_{\text {soil }, n, \max }=(F C-W P) \times \text { Thickness }_{n}, \\
\text { mosit }_{n}=A V W_{\text {soil, }, n} / A V W_{\text {soil }, \text { max }_{\text {max }},} \\
w f p s_{n}=Q_{n} / S A T .
\end{gathered}
$$




\subsection{Radiation transmission and energy partitioning}

The incipient solar radiation $\left(\mathrm{Srad} ; \mathrm{W}^{\mathrm{m}} \mathrm{m}^{2}\right.$ ) is intercepted in turn by the overstory and then the understory canopy, and finally absorbed by the soil surface. The canopy is divided into sunlit and shaded fractions, in which photosynthesis and evapotranspiration is estimated independently. The solar radiation intercepted by the crown of the PFT $i$ is calculated as:

$$
\left.\begin{array}{l}
\operatorname{Rad}_{a b s, r, i}=e \operatorname{Rad}_{r, i} \times\left(1-e^{k_{e x t, r, j} \times L A I_{i}}\right), \\
\operatorname{Rad}_{\text {trans }, r, i}=e \operatorname{Rad}_{r, i}-\operatorname{Rad}_{a b s, r, i}, \\
\operatorname{Rad}_{a b s, s u n l i t, r, i}=k_{\text {ext }, i} \times e \operatorname{Rad}_{r, i} \times L A I_{i}, \\
\operatorname{Rad}_{a b s, \text { shade }, r, i}=\operatorname{Rad}_{a b s, r, i}-\operatorname{Rad}_{a b s, s u n l i t, r, i} .
\end{array}\right\}
$$

Where $r$ denotes the type of radiation $\left(\mathrm{Rad}, \mathrm{W} / \mathrm{m}^{2}\right)$, either shortwave solar radiation (SW) or photosynthetic active radiation (PAR); abs and trans denote the absorbed and transmitted light, respectively; sunlit and shade denote the sunlit and the shaded canopies, respectively; $k_{e x t, i} i$ is the light extinction coefficient of the PFT $i$; $L A I_{i}$ is the leaf-area index of the PFT $i$; and $e R a d_{r, i}\left(W^{2} / m^{2}\right)$ is the effective radiation absorbed or transmitted through the canopy:

$$
\operatorname{eRad}_{r, i}=\operatorname{inRad}_{r} \times\left[1-\alpha_{r, i} \times\left(1-f_{\text {snow }, i}\right)-\alpha_{\text {snow }} \times f_{\text {snow }, i}\right] .
$$

Where subscription $r$ denotes type of radiation (SRAD or PAR). For the overstory $(o)$, the incipient radiation is the $S R A D$ or the $P A R$. For the understory $(u)$, the incipient radiation is the transmitted radiation energy through the canopy of the overstory $\left(\operatorname{Rad}_{\text {trans }, o, r}\right) . a_{r, i}$ is the reflection coefficient of PFT $i$ to the radiation type $r$; $a_{\text {snow }}$ is the reflection coefficient of the snow (the default value is 0.69 ); $f_{\text {snow }, i}$ is the fraction of the leaves covered by the snow, calculated as:

$$
f_{\text {snow }, i}=w_{i, \text { snow }} / w_{i, \max } \text {. }
$$

Where $w_{i, \text { snow }}$ is the snow water equivalent $(\mathrm{mm})$ intercepted by the leaf of PFT $i$; $w_{i, \max }(\mathrm{mm})$ is a PFT specific parameter that defines the water holding capacity of the leaf.

Radiation transmitted ( $\operatorname{Rad}_{\text {trans }, u}$ ) through the understory canopy would be absorbed by the surface soil and drive processes such as evaporation and snow sublimation/melting:

$$
\left.\begin{array}{l}
\operatorname{Rad}_{\text {abs,srad }, \text { soil }}=\left(1-f_{\text {snow }}\right) \times \operatorname{Rad}_{\text {trans }, u} \times\left(1-\alpha_{\text {soil }}\right), \\
\operatorname{Rad}_{\text {abs,srad }, \text { snow }}=f_{\text {snow }} \times \operatorname{Rad}_{\text {trans }, u} \times\left(1-\alpha_{\text {snow }}\right) .
\end{array}\right\}
$$

Where $R a d_{a b s, s r a d, s o i l}$ and $R a d_{a b s, s r a d, \text { snow }}$ are the energies absorbed by snow-covered or bare soil, respectively; $a_{\text {soil }}$ is the reflection coefficient of wet soil (default value is 0.13 ). $f_{\text {snow }}$ is the fraction of the ground covered by packed snow.

\subsection{Balance of the leaf intercepted water and snow pool}

The daily balance of the leaf intercepted water pools of PFT $i$ are calculated as:

$$
\left.\begin{array}{l}
\Delta W_{\text {snow }, i}=\text { incptSnow }_{i}-\text { sublimate }_{i}-\text { Through }_{\text {snow }, i}, \\
\Delta W_{\text {water }, i}=\text { incptWater }_{i}-\text { Evp }_{i}-\text { Through }_{\text {water }, i} .
\end{array}\right\}
$$

Where $W_{\text {sonw }}$ and $W_{\text {water }}$ are the leaf intercepted snow and water pool. Subscription $i$ denotes PFT; incptWater ${ }_{i}$ and incptSnow $_{i}(\mathrm{~mm} /$ day) are the daily intercepted water or snow (equivalent water) by the crown of PFT $i$, respectively; $E v p_{i}$ and sublimate $_{i}(\mathrm{~mm} /$ day) are the daily evaporation and snow-sublimation rate from the crown respectively; Therough $h_{\text {water, } i}$ and Through $_{\text {snow }, i}(\mathrm{~mm} /$ day) are the daily throughfall in form of rain and snow, respectively.

$$
\left.\begin{array}{l}
\text { incptWater }_{i}=k_{w, i} \times k_{\text {allside }, i} \times \text { LAI }_{i} \times \text { rain }, \\
\text { incptSnow }_{i}=k_{w, i} \times k_{\text {allside }, i} \times \text { LAI }_{i} \times \text { snow } .
\end{array}\right\}
$$

Where rain and snow (mm/day) are the incipient rain and snow to the canopy, respectively. For the overstory, rain 
equal to the daily rainfall, and snow equal to the daily snowfall. For the understory, rain and snow are the throughfall of the rainwater $\left(\right.$ Through $\left.h_{\text {water, },}\right)$ and the snow $\left(\right.$ Through $\left._{\text {snow,o },}\right)$ from the canopy of the overstory, respectively. $K_{w, i}\left(\mathrm{~mm} \mathrm{H}_{2} \mathrm{O} / \mathrm{LAI}\right)$ is the $P F T$ specific water interception coefficient of the crown; $k_{\text {allside }, i}$ is the ratio between the all-sided $L A I$ and the projected $L A I$.

The daily flux of snow sublimation is the minimum of intercepted snow $\left(W_{\text {snow }, i}\right)$ and amount of snow that can be evaporated by the leaf absorbed solar radiations.

$$
\begin{gathered}
\text { Sublimate }_{i}=\operatorname{Min}\left(W_{\text {snow }, i}, \text { Rad }_{\text {abs srad }, i} /(\lambda+\kappa)\right), \\
\lambda=2.5104 \times 10^{6}-2430.54 \times T_{\text {avg }} .
\end{gathered}
$$

Where $\operatorname{Rad}_{\text {abs,srad,i }}\left(\mathrm{W} / \mathrm{m}^{2}\right)$ is the solar radiation absorbed by crown of the PFT $i ; \lambda\left(\mathrm{KJ} /\left(\mathrm{mm} \cdot \mathrm{m}^{2}\right)\right)$ is the latent heat of vaporization of water; $\kappa\left(0.3336 \times 10^{6} \mathrm{KJ} /\left(\mathrm{mm} \cdot \mathrm{m}^{2}\right)\right)$ is latent heat fusion; $T_{a v g}\left({ }^{\circ} \mathrm{C}\right)$ is the daily mean air temperature (see section 1 of the Appendix).

If $\operatorname{Rad}_{a b s, s r a d, i}$ cannot melt and vaporize all the intercepted snow water, and $W_{\text {snow }, i}+$ incptSnow $_{i}-$ sublim ate $_{i}$ is larger than the water holding capacity of the leaf, $W_{i, \max }(\mathrm{mm})$, then the excessive snow will become throughfall,

$$
\text { Through }_{\text {snow }, i}=W_{\text {snow }, i}+\text { incptSnow }_{i}-\text { Sublimate }_{i}-W_{i, \max } \text {. }
$$

Otherwise, after $W_{\text {sonw,i }}$ is completely sublimated, the remaining leaf-absorbed solar energy ( $\Delta R a d$ ${ }_{a b s, \text { srad }, i}=E_{\text {sublimate }, i}=$ Sublimate $_{i} \times(\lambda+\kappa)$ ) will be available to vaporize the leaf-intercepted water of the PFT $i$ (i.e. $\left.W_{\text {water }, i}\right)$. The daily evaporation rate (i.e. $E v p_{i}$ ) is the minimum of the leaf-intercepted-water and the potential evapotranspiration rate $\left(P E T_{i} ; \mathrm{mm} /\right.$ day $)$ driven by the remnant $\operatorname{Rad}_{\text {als srad }, i}$,

$$
E v p_{i}=\operatorname{Min}\left(W_{\text {water }, i}, P E T_{i}\right) \quad\left(\text { Where } P E T_{i}=f\left(\operatorname{Rad}_{\text {als,srad }, i}\right)\right) .
$$

Where the water-heat exchange $\left(f\left(\operatorname{Rad}_{a b s, s r a d, i}\right)\right)$ is estimated using the Penman-Monteith approach (Wigmosta et al., 1994).

After the intercepted-leaf water is completed vaporized, the remaining leaf-absorbed solar energy will be available to drive the transpiration which extracts water from the soil.

Balance of the ground snow is calculated as:

$$
\begin{aligned}
& \text { Sublimate }_{\text {soil }}=\operatorname{Min}\left(W_{\text {soil }, \text { snow }}, \frac{\operatorname{Rad}_{\text {abs,srad,snow }}}{\lambda+\kappa}\right) \quad\left(T_{\text {day }} \leq 0^{\circ} \mathrm{C}\right), \\
& \text { Snowmelt }=\operatorname{Min}\left(W_{\text {soil }, \text { snow },} P_{t, \text { melt }} \times T_{\text {day }}+\frac{R a d_{\text {abs, srad,snow }}}{\kappa}\right) \quad\left(T_{\text {day }}>0^{\circ} \mathrm{C}\right), \\
& \Delta W_{\text {soil,snow }}=\text { Through }_{\text {snow }}-\text { Sublimate }_{\text {soil }}-\text { Snowmelt } .
\end{aligned}
$$

Where $W_{\text {soil,snow }}(\mathrm{mm})$ is the water equivalent ground snow; $R a d_{a b s, s r a d, \text { snow }}$ is the radiation energy absorbed by snow-covered ground; $\lambda\left(\mathrm{KJ} /\left(\mathrm{mm} \cdot \mathrm{m}^{2}\right)\right)$ is the latent heat of vaporization of water; $\kappa\left(0.3336 \times 10^{6} \mathrm{KJ} /\left(\mathrm{mm} \cdot \mathrm{m}^{2}\right)\right)$ is latent heat fusion; $P_{t, \text { melt }}=0.65\left(\mathrm{~kg} /\left(\mathrm{m}^{2} \cdot{ }^{\circ} \mathrm{C} \cdot\right.\right.$ day $\left.)\right)$ is the coefficient of snow melt with temperature (Coughlan and Running, 1997).

\subsection{Water movement in soil}

The dynamics of the soil water pools is computed as:

$$
\left.\begin{array}{l}
\Delta W_{\text {soil }, 1_{1}}=\text { Through }_{w, u}+\text { Snowmelt }- \text { Evp }_{\text {soil }}-\text { Runoff }_{\text {sf }}-\text { Percolation }_{1}-\text { Tran }_{1}, \\
\Delta W_{\text {soil }, n}=\text { Percolation }_{n-1}-\text { percolation }_{n}-\text { Tran }_{n} \quad(n>1), \\
\text { Runoff }=\text { Runoff }_{\text {sf }}+\text { Percolation }_{\mathrm{N}} .
\end{array}\right\}
$$

Where $W_{\text {soil }, 1}(\mathrm{~mm})$ is the water storage of the first soil layer; $W_{\text {soil, } n}$ is the water storage of the $\mathrm{n}^{\text {th }}$ soil layer; Through $_{s, u}$ and Through $h_{s, u}$ are the rain and the snow throughfall from the understory canopy, respectively; 
Sublimate $_{\text {soil }}$ and Snowmelt ( $\mathrm{mm} /$ day) are the sublimation and melting rate of ground snow, respectively (see section 2.6); $E v p_{\text {soil }}(\mathrm{mm} /$ day) is the evaporation of water from the top soil layer, estimated as the minimum of available water in the surface soil layer and the potential evapotranspiration rate ( $P E T_{\text {soil }}, \mathrm{mm} /$ day), driven by the soil-absorbed radiation; Runoff and Runoff sf $_{\text {( }}(\mathrm{mm} /$ day) are daily total runoff and surface runoff of water accumulation, respectively; and $\operatorname{Percolation}_{\mathrm{N}}(\mathrm{mm} / \mathrm{day})$ is the water percolation from the $\mathrm{n}^{\text {th }}$ soil layer. $\operatorname{Tran}_{n}\left(\mathrm{~mm} /\right.$ day) is the water extracted from the $\mathrm{n}^{\text {th }}$ soil layer for transpiration by the roots of the vegetation.

AEM-DV applied a modified Soil Conservation Service (SCS) curve number (CN) model developed by United States Department of Agriculture (1986) to estimate the surface runoff,

$$
\begin{gathered}
\text { Runoff }_{s f}=\frac{p \times p}{p+s}, \\
P=\text { Through }_{w, u}+\text { Snowmelt, } \\
S=\frac{25400}{C N^{\prime}}-254 .
\end{gathered}
$$

Where $P(\mathrm{~mm} /$ day) is the effective water input; $S(\mathrm{~mm})$ is the potential maximum water retention by soil.

$$
C N^{\prime}=\frac{3.0646 \times e^{0.0235 \times \text { moisto }} \times C N}{10+\left[\left(0.030646 \times e^{0.0235 \times m o i s t o}-0.1\right) \times C N\right]} .
$$

Where $C N$ ' is the moisture adjusted curve number $(C N)$ based on the research of Elhakeem and Papanicolaou (2009); $C N$ is the empirical curve number for the SCS-CN runoff model provided by United States Department of Agriculture (1986); CN is related soil texture and LCFT; moist0 (see section 2.3) is the soil mostiure of the top soil layer.

The downward movement of water among soil layers (i.e. Percolation) is addressed with the simple Versatile Budget model of Baier and Robertson (1966). The water budget models which have successfully simulated soil water in arid ecosystems in several studies (Noble and Crisp, 1979; Kemp et al., 1997), have fewer parameters to estimate and are not strongly affected by boundary conditions soil heterogeneity, hysteresis, and other factors that can introduce errors into mechanistic models (Mustafa et al., 1983). Unlike the original Versatile Budget model which requires empirical determinations relating actual evapotranspiration to soil water content, AEM-DV simulates the transpiration and the water uptake rate based on the plant physiological mechanisms and makes rooting density a function of plant community.

\section{Population dynamics}

In AEM-DV, vegetation dynamic is determined by population dynamics of the PFTs that coexist and compete for light, water, and soil $\mathrm{N}$ resources in an ecosystem. The annual dynamic of population density is determined by the balance between plant establishment rate $\left(E s t a b\right.$, number of seedlings $\left./ \mathrm{m}^{2}\right)$ and plant mortality rate (Mort, $\left.0-1\right)$, which are further constrained by climatic stress, resource availability, and the AIP growth rate.

$$
\Delta \text { Density }_{i}=\text { Estab }_{\text {bioclim }, i_{i}} \times \text { Estab }_{i}-\operatorname{Min}\left(\left(\text { Mort }_{\text {bioclim }, i}+\text { Mort }_{\text {light }, i}+\text { Mort }_{i}\right), 1\right) \times \text { Density }_{i} .
$$

Where $E_{s t a b} b_{\text {bioclim, } i}(0$ or 1$)$ determines the bioclimatic constrains on establishment. Annual precipitation is the major bioclimatic constrain in dryland. If current annual precipitation exceeds the minimum requirement $\left(P P T_{\text {min,estaa }}\right.$; Appendix Table A1) of a PFT, Estab bioclim,$i=1$, and the PFT will be allowed to establish in the spring. Otherwise, Estabbioclim,$i=0$. Estab bioclim,$i\left(0\right.$ or 1) $E_{\text {stab }}$ bioclim,$i$ is the mortality rate caused by long-term climatic stress, which is represented by the climate mean in the past 20 year. The population of a PFT will die out (Estab bioclim,$i_{i}=1$ if the long-term annual precipitation of the patch it locates in becomes smaller than its minimum precipitation threshold ( $P P T_{\text {min,mort }}$ ). Otherwise or for a managed ecosystem where the PFT is already known, Estab $b_{\text {bioclim }, i}=0$. Estab bioclim,$i=0$ is the mortality rate due to light or space competition; and $\mathrm{Mort}_{i}$ is the background mortality rate of the PFT $i$. 


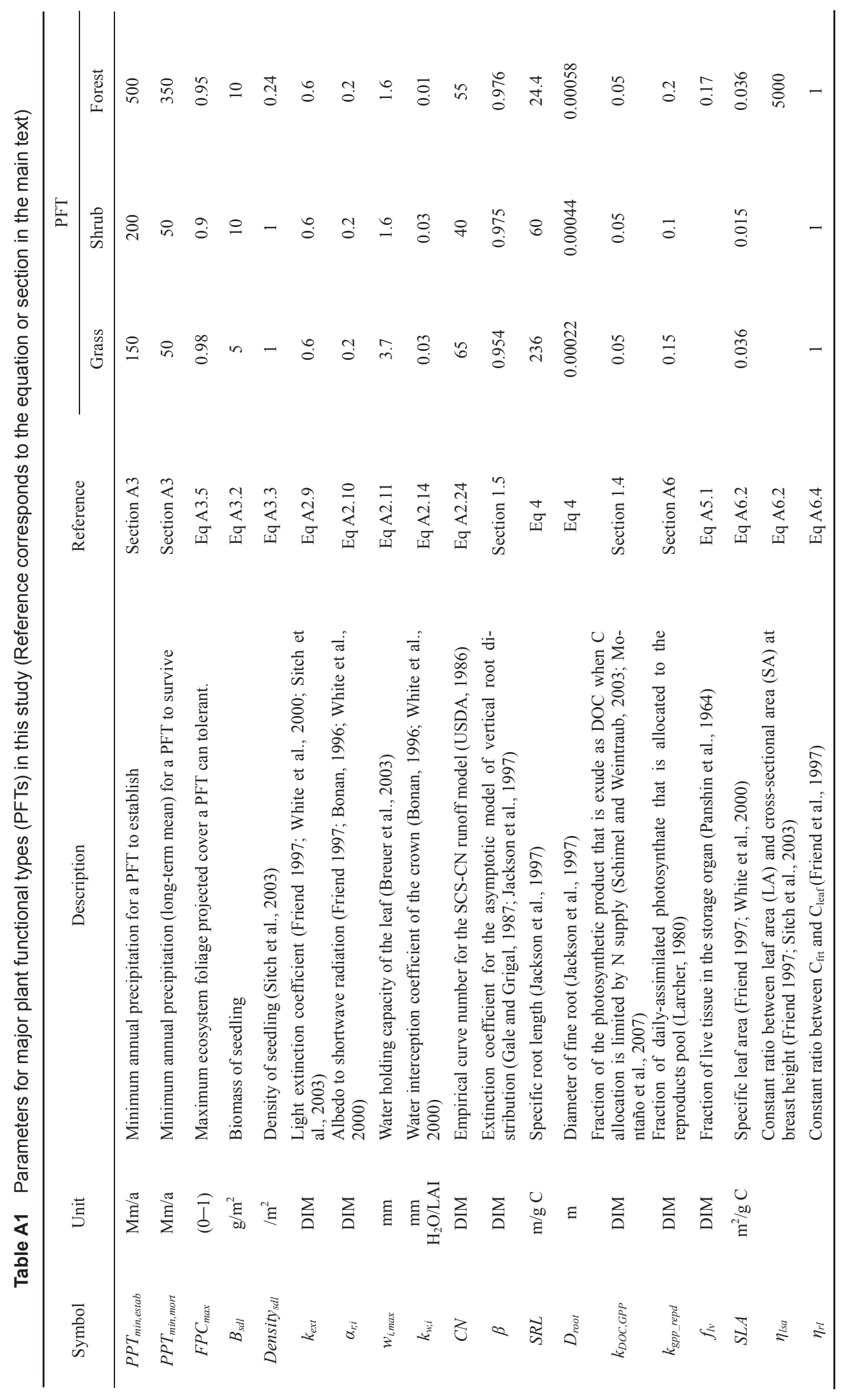




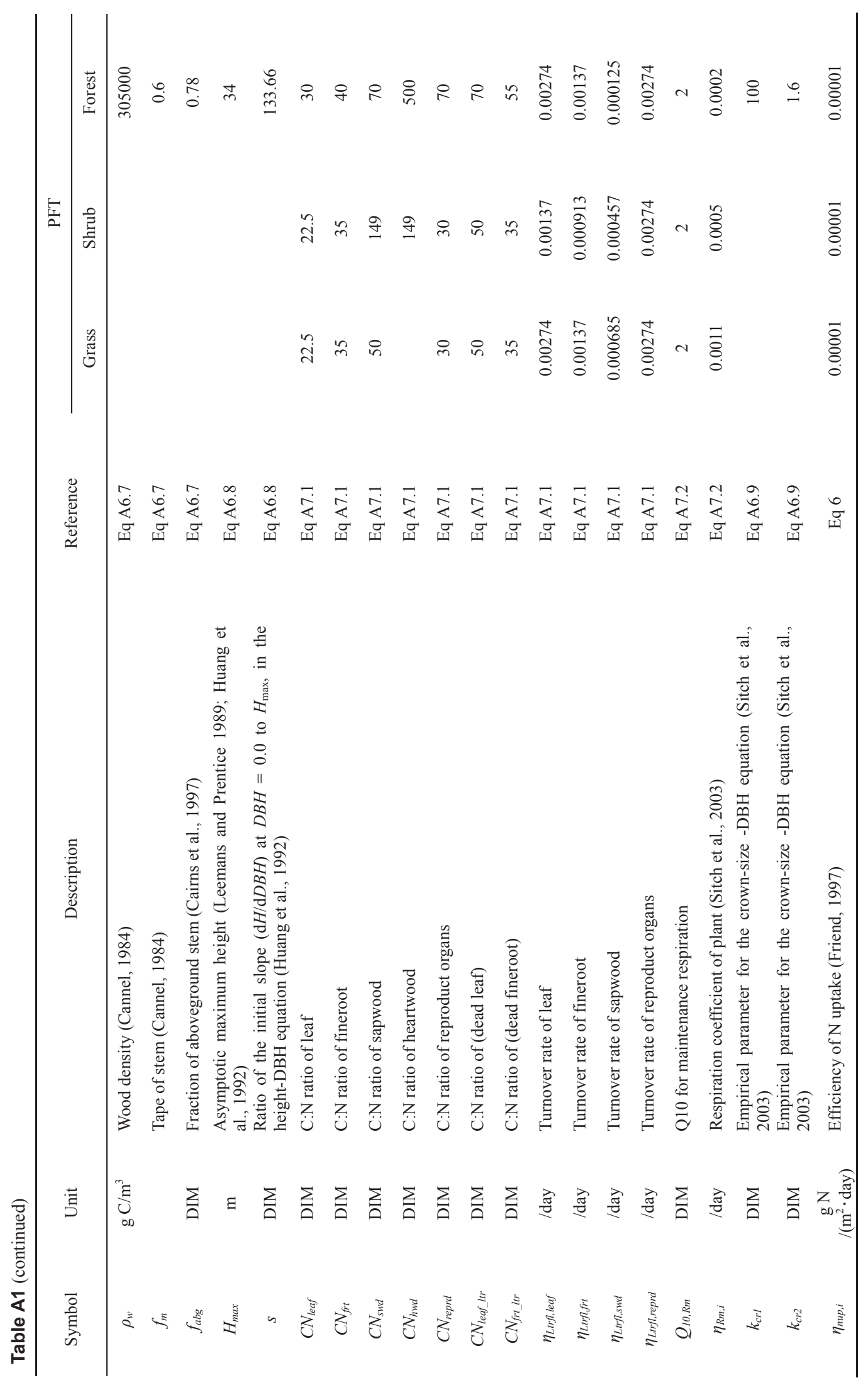




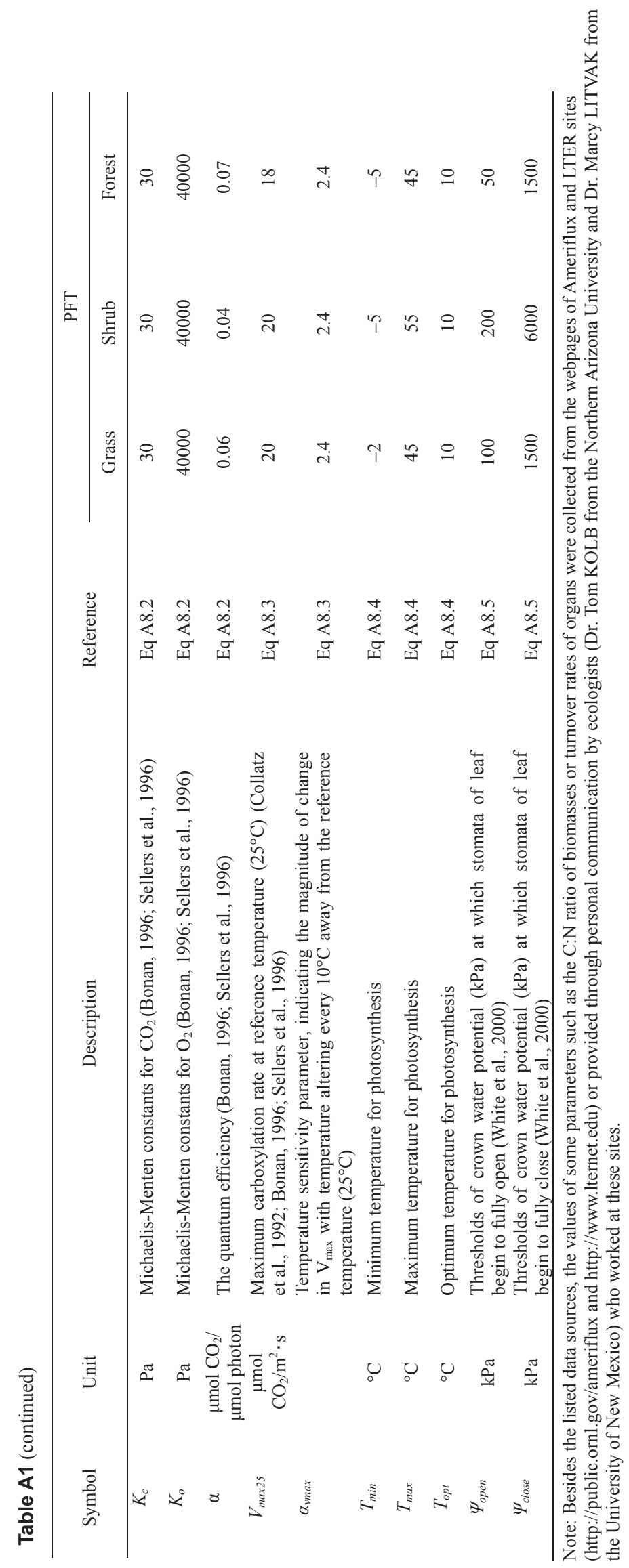


The total biomass of new seedlings is added to the population of PFT $i$, and both the Density $y_{i}$ and biomass of $A I P_{i}$, are modeled as:

$$
\left.\begin{array}{l}
\text { Density }_{i, t}=\text { Density }_{i, t-1}+\text { Estab }_{i}, \\
B_{i, t}=\left(B_{i, t-1} \times \text { Density }_{i, t-1}+B_{s d l, i} \times \text { Estab }_{i}\right) / \text { Density }_{i, t} .
\end{array}\right\}
$$

Where $t-1$ denotes the value of the last time-step, and $t$ denotes the updated value. $B_{i, t}, B_{i, t 1}$ and $B_{s d l, i}\left(\mathrm{~g} / \mathrm{m}^{2} \cdot \mathrm{plant}\right)$ are the biomass of the updated AIP, original AIP, and individual seedling, respectively. Constrained by light availability, seedlings can only establish in spaces not shaded by the vegetation canopy.

$$
\text { Estab }_{i}=\text { Density }_{\text {sdl }, i} \times\left(1-F P C_{0}\right),
$$

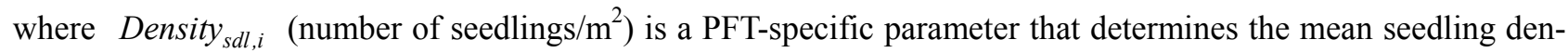
sity in an open space; $\mathrm{FPC}_{0}$ is the foliage projective coverage (FPC; $\left.0-1\right)$ of the canopy c, i.e. the fraction of ground shaded by canopy $\mathrm{c}$. If $\mathrm{i} \in$ overstory, $\mathrm{c}$ refers to the overstory; otherwise, $\mathrm{c}$ includes both the overstory and understory. FPCc is the aggregated FPC of all populations that belong to canopy c. The FPC of population $i$ $\left(F P C_{p, i}\right)$ is calculated from the FPC of its AIP and crown area:

$$
F P C_{0}=\sum_{i e c} F P C_{p, i}=\sum_{i e c}\left(F P C_{i} \times C A_{p, i}\right)=\sum_{i e c}\left[F P C_{i} \times\left(C A_{i} \times \text { Density }_{i}\right)\right] .
$$

Where $C A_{p, i}$ ( $\mathrm{m}^{2} /$ population) is the crown area of population i. $F P C_{i}$ and $C A_{i}\left(\mathrm{~m}^{2} /\right.$ crown) are the FPC and the crown size of the $A I P_{i}$, respectively.

When the aggregated $\mathrm{FPC}$ of an ecosystem exceeds the maximum value $\mathrm{FPC}_{\max }<1$, the PFT is stressed by a light deficit. Sciophytes have higher $\mathrm{FPC}_{\max }$ than heliophytes. The mortality due to light competition is estimated as:

$$
\text { Mort }_{\text {light }, i}=\left(F P C-F P C_{\max }\right) / F P C .
$$

Where FPC is the aggregated FPC of all plants in an ecosystem. Following Sitch et al. (2003), the background mortality rate is inversely related to the growth efficiency rate ( greff ), which depends on the $\mathrm{C}$ balance of the vegetation in the previous 365 days:

$$
\operatorname{greff}_{i}=\sum_{t=d-365}^{d}\left(N P P_{t, i}-L_{T R F L_{t, i}}\right) / V E G C_{i} .
$$

Where $N P P_{t, i}\left(\mathrm{~g} \mathrm{C} / \mathrm{plant} \cdot\right.$ day) is the daily net primary productivity, $L T R F L_{t, i}(\mathrm{~g} \mathrm{C} / \mathrm{plant} \cdot$ day) is the daily litter fall rate, and VEGC ( $\mathrm{g} \mathrm{C} /$ plant) is the vegetation $\mathrm{C}$ of the AIP.

A process-based biogeochemical model is developed to simulate NPP and other water, C, and N fluxes in an ecosystem, and a tree form model is developed to model the structure and CA of an AIP.

\section{Nitrification and denitrification}

Some of ammonium produced during decomposition is converted into nitrate through nitrification process. Following Lin et al. (2000) AEM-DV models nitrification rate (nitrification, $\mathrm{g} \mathrm{N} /\left(\mathrm{m}^{2} \cdot\right.$ day)) as a function of soil temperature, soil water content and $\left[\mathrm{NH}_{4}{ }^{+}\right]$,

$$
\text { Nitrification }=k_{\text {nit }} \times k T_{n i t} \times k W_{n i t} \times\left[\mathrm{NH}_{4}\right] \text {. }
$$

Where $k_{\text {nitf }}\left(\mathrm{g} \mathrm{N} /\left(\mathrm{m}^{2} \cdot\right.\right.$ day $)$ ) is the potential nitrification rate (with default value of 0.003$) ; k T_{\text {nit }}$ is the temperature factor as described by Riedo et al. (1998):

$$
k T_{\text {nit }}=Q_{10, \text {, it }}^{\left(\left(T_{\text {soi }}-T_{\text {opt }, \text { iit }}\right) / 10\right)} .
$$

Where $T_{o p t, n i t}=20^{\circ} \mathrm{C}$ is the optimum temperature, and $Q_{10, n i t}=2$.

$k W_{n i t}$ is the moisture scalar, which is assumed to be related linearly to soil water content with a slope of 1.17 and an intercept of 0.165 when soil water content is below field capacity; and with a slope decreased to 0.1 when soil water is above field capacity (Riedo et al., 1998). 


$$
\left.\begin{array}{ll}
k W_{n i t}=\frac{1.17 \times Q_{0}}{F C}+0.165 & Q_{0} \leq F C, \\
k W_{n i t}=1.0-\frac{0.1 \times Q_{0}}{F C} & Q_{0}>F C .
\end{array}\right\}
$$

Denitrification is an anaerobic process that is carried out by denitrifying bacteria, which involves metabolic reduction of nitrate and nitrite into denitrogen and nitrous oxide gas. In denitrification rate (denitrification, $\mathrm{g} \mathrm{N} /\left(\mathrm{m}^{2} \cdot\right.$ day $\left.)\right)$ is also a function of soil temperature, soil water content and nitrate concentration:

$$
\left.\begin{array}{l}
\text { Denitrification }=k_{\text {denitrif }} \times k T_{\text {denitrif }} \times k W_{\text {denitrif }} \times\left[N O_{y}\right], \\
k T_{\text {denitrif }}=Q_{10, \text { nit }}^{\left(\left(T_{\text {soi }}-T_{\text {opt,denitri }}\right) / 10\right)}, \\
k W_{\text {denitrif }}=0 \quad Q_{0} \leq F C, \\
k W_{\text {denitrif }}=\frac{Q_{0}-F C}{S A T-F C} \quad Q_{0}>F C .
\end{array}\right\}
$$

Where $k_{\text {denitrif }}\left(\mathrm{g} \mathrm{N} /\left(\mathrm{m}^{2} \cdot\right.\right.$ day)) is the potential denitrification rate (with default value of 0.0015$) ; T_{\text {opt,denitrify }}=25^{\circ} \mathrm{C}$ is the optimum temperature for denitrification; $Q_{10 \text {,denitrif }}=3.0 ; Q_{0}, F C$, and $S A T$ are the water content of topsoil, field capacity and saturated water content respectively.

\section{Assessing the storage capacity $\left(C_{\text {store, max }}\right.$ and $\left.N_{\text {store,max }}\right)$}

In the woody PFT, storage pools are located in the sapwood; while in the non-woody PFT, storage pools are located in the root. The maximum storage capacity of a plant is calculated as:

$$
\left.\begin{array}{l}
C_{\text {store }, i, \max }=f_{\text {sto }} \times f_{\text {lv }} \times C_{\text {storage_organ }}, \\
N_{\text {store }, i, \max }=C_{\text {store, }, \text { max }} / C N_{i, \text { min }} .
\end{array}\right\}
$$

Where $C_{\text {store,i,max }}$ (g C/plant) and $N_{\text {store, }, \text { max }}(\mathrm{g} \mathrm{N} /$ plant) are the maximum $\mathrm{C}$ and $\mathrm{N}$ storage capacity, respectively. $f_{s t o}=0.67$ is the fraction of the live storage organ that can be used as storage (Friend et al., 1997); $f_{l v}$ is the fraction of live tissue in the storage organ. For the broadleaf $P F T, f_{l v}=0.17$; for the needleleaf $P F T, f_{l v}=0.07$ (Panshin et al., 1964). $C N_{i, \min }$ is the minimum C:N ratio among organs of the $P F T i$. AEM-DV uses this value to approximate the minimum $\mathrm{C}: \mathrm{N}$ ratio of the storage pools.

\section{Allocation of photosynthate and $\boldsymbol{N}_{\text {store }}$ to maintain AIP form}

The allocation routine considers the basic functional constraints between the different tree parts, with nitrogen allocation following carbon allocation, using mostly empirical principles. First, a fraction $\left(k_{\text {gpp_repd }}\right.$, ranging from $5 \%$ to $35 \%$ ) of the photosynthate is allocated to the reproductive pool (Larcher, 1980). Then, the remaining photosynthate is added to $C_{\text {store }}$ and will be allocated to different live, structural organs (i.e. leaf, sapwood, and fine root). Non-live tissues such as heartwood will not be changed by allocation. Following $\mathrm{C}$ allocation, $\mathrm{N}$ is partitioned so as to maintain constant C:N ratios of each organ. If the demand for $\mathrm{N}$ exceeds $N_{\text {store }}$, plant growth is limited and excessive $\mathrm{C}$ is added to $C_{\text {store }}$. In this case, a fraction of the increased $C_{\text {store }}\left(G P P_{\text {excs }}\right)$ enters the soil as dissolved organic $\mathrm{C}$, stimulating microbial processes and enhancing the rate of $\mathrm{N}$ mineralization (Schimel and Weintraub, 2003; Montaño et al., 2007).

$\mathrm{C}$ allocation to the live, structural organs takes place on a daily time step to maintain the form of the plant (i.e. the ratios of $\mathrm{C}$ among live structural organs). A non-woody PFT is assumed to have a fixed form throughout its lifespan, while the form of a woody plant is updated annually, based on three constraints: 1) foliage area is assumed to be linearly proportional to sapwood area at breast height; 2) the ratio of foliage and fine root $\mathrm{C}$ mass is fixed; 3 ) the allometric relationship between diameter at breast height ( $\mathrm{DBH}$, meter) and woody $\mathrm{C}$ mass is fixed. When the form of a woody plant is updated, stem diameter, crown properties, and biomass (C pool size) of its organs are updated.

Before the tree form is updated, the total $\mathrm{C}\left(A V C_{\text {livestruct }}\right)$ and $\mathrm{N}\left(A V N_{\text {livestruct }}\right)$ that are available to constructing 
the live structural organs are calculated as:

$$
\left.\begin{array}{l}
A V C_{\text {livestruct }}=C_{\text {old,leaf }}+C_{\text {old,swd }}+C_{\text {old, frt }}+C_{\text {old,store }}, \\
A V N_{\text {livestruct }}=N_{\text {old,leaf }}+N_{\text {old,swd }}+N_{\text {old, frt }}+N_{\text {old,store }}, \\
A V C_{\text {livestruct }}=C_{\text {leaf }}+C_{\text {swd }}+C_{\text {frt }} .
\end{array}\right\}
$$

Where $C_{\text {old }}$ (g C/plant) and $N_{\text {old }}$ (g N/plant) indicate the $\mathrm{C}$ and $\mathrm{N}$ pools of the organs before updating, while $\mathrm{C}$ (g $\mathrm{C} /$ plant) in the equation indicates the updated $\mathrm{C}$ pool size. All other subscripts denote different live structural organs and the storage pools.

According to the "pipe model" theory (Shinozaki et al., 1964):

$$
L A=S L A \times C_{\text {leaf }}=\eta_{\text {lsa }} \times S A \text {. }
$$

Where $L A\left(\mathrm{~m}^{2}\right)$ is the leaf area; $S A\left(\mathrm{~m}^{2}\right)$ is the sapwood cross-sectional area; $\eta_{l s a}$ is the constant ratio between $L A$ and $S A . S L A$ is the specific leaf area $\left(S L A, \mathrm{~m}^{2} / \mathrm{g} \mathrm{C}\right)$. It is a parameter that converts the leaf $\mathrm{C}\left(\mathrm{C}_{\text {leaf }}, \mathrm{g} / \mathrm{plant}\right)$ to $L A$. $S A$ is calculated from the diameter of the stem at the breast height $(D B H, \mathrm{~m})$ :

$$
S A=\left[C_{s w d} /\left(C_{s w d}+C_{h w d}\right)\right] \times \pi \times(D B H / 2)^{2} .
$$

As mentioned before, leaf is also functionally related to the fine root:

$$
C_{\text {frt }}=\eta_{r 1} \times C_{\text {leaf }} \text {. }
$$

Where $\eta_{r l}$ is the constant ratio between $C_{f r t}$ and $C_{\text {leaf }}$. From equation A6.1 and equation A6.4, we have

$$
C_{\text {swd }}=A V C_{\text {livestruct }}-C_{\text {leaf }}-C_{\text {froot }}=A V C_{\text {livestruct }}-\left(1+\eta_{r 1}\right) \times C_{\text {leaf }} \text {. }
$$

From equation A6.2, equation A6.3, and equation A6.5, we have

$$
\begin{aligned}
& C_{\text {swd }}=C_{\text {livestruct }}-\left[\left(1+\eta_{r l}\right) \times \eta_{r l} / S L A\right] \times S A \\
& =C_{\text {livestruct }}-\left[\left(1+\eta_{r 1}\right) \times \eta_{1 s a} / S L A\right] \times\left[C_{s w d} /\left(C_{s w d}+C_{h w d}\right)\right] \times \pi \times(D B H / 2)^{2}
\end{aligned}
$$

In the equation A6.6, only $\mathrm{C}_{\mathrm{swd}}$ and $\mathrm{DBH}$ are unknown. Both variables are related to the volume of the stem $\left(\mathrm{V}_{\text {stem }}, \mathrm{m}^{3}\right)$ :

$$
\left.\begin{array}{c}
V_{\text {stem }}=f_{\text {abg }} \times\left(C_{s w d}+C_{h w d}\right) / \rho_{w}, \\
V_{\text {stem }}=f_{m} \times \pi \times(D B H / 2)^{2} \times H,
\end{array}\right\}
$$

So, $f_{a b g} \times\left(C_{s w d}+C_{h w d}\right) / \rho_{w}=f_{m} \times \pi \times(D B H / 2)^{2} \times H$.

Where $\rho_{w}\left(\mathrm{~g} \mathrm{C} / \mathrm{m}^{3}\right)$ is the wood density; $f_{m}$ is an empirical factor that determines the tape of stem (Cannell, 1984); $f_{a b g}$ is the fraction of aboveground stem (Cairns et al., 1997); $H(\mathrm{~m})$ is the height to the apex. To calculate $\mathrm{H}$ from DBH, AEM-DV adopts an empirical allometric equation which was the best height-diameter equation in the study of Huang et al. (1992) and has also been widely used in other studies (Leemans and Prentice 1989; Pacala et al. 1993; Fulton, 1999):

$$
H=H_{0}+\left(H_{\max }-H_{0}\right) \times\left[1-e^{-s \times D B H /\left(H_{\max }-H_{0}\right)}\right] .
$$

Where $H_{0}=1.37(\mathrm{~m})$ is the breast height; $H_{\max }$ is the asymptotic maximum height (m); and $\mathrm{s}$ is the ratio of the initial slope $(d H / d D B H)$ at $D B H=0.0$ to $H_{\text {max }}$. By simultaneously solving the equation A6.6, A6.7, and A6.8, AEM-DV derives the value of $D B H, H$, and $C_{s w d}$. Then equation A6.2 and A6.1 are used to update the $C_{\text {leaf }}$ and $C_{f r t}$. Next, the required $\mathrm{N}\left(R Q N_{\text {livestruct }}=N_{\text {leaf }}+N_{\text {swd }}+N_{\text {frt }}\right)$ is estimated according to the C:N ratios of the organs. If the required $\mathrm{N}$ exceeds the available $\mathrm{N}$ (i.e. $A V N_{\text {livestruct }}$, equation A6.1), $A V C_{\text {livestruct }}$ will be shrank by multiplying $A V N_{\text {liveStruct }} / R Q N_{\text {livestruct }}$, and the tree form updating process will reiterate until $R Q N_{\text {liveStruct }} \leq A V N_{\text {livestruct }}$. Finally, the ratios of biomasses among different organs are updated.

AEM-DV uses an empirical model (Zeide, 1993) to calculate the crown size (i.e. CA) from a plant's $D B H$. When canopy close, crowns of all AIPs will cease expanding.

$$
C A_{i}=K_{c r 1} \times D B H_{i}^{k_{c r} 2} \text {. }
$$

Where $K_{c r 1}$ (default value=100) and $K_{c r 2}($ default value=1.6) are empirical parameters (Sitch et al., 2003). The LAI 
of crown $i\left(L A I_{i}\right)$, sunlit crown $\left(L A I_{i, s u n l i t}\right)$, shaded crown $\left(L A I_{i \text {,shade }}\right)$, and FPC are then calculated as:

$$
\left.\begin{array}{l}
L A I_{i}=l A_{i} / C A_{i}, \\
L A I_{i, \text { sunlit }}=1-\exp \left(-L A I_{i}\right), \\
L A I_{i, \text { shade }}=L A I_{i}-L A I_{i, \text { sunlit }}, \\
F P C_{i}=1-\exp \left(-0.5 \times L A I_{i}\right) .
\end{array}\right\}
$$

\section{Photosynthesis, turnover and the respiration of organs}

\subsection{Turnover of tissues}

AEM-DV assumes that a fixed fraction of an organ's tissue will die and be transferred to either the litter pools or the heartwood (in the case of sapwood) every day. Since the C:N ratio of the litter pool and dead wood are usually larger than the live tissues, tissue turnover may result in $\mathrm{N}$ resorption.

$$
\left.\begin{array}{l}
\operatorname{Ltrfl}_{i}=\sum_{o} \text { Ltrfl }_{i, o}, \\
\operatorname{Ltrfl}_{i, o}=\eta_{\text {Ltrfl,i,o }} \times C_{i, o}, \\
\Delta N_{\text {store }, i}=\text { Nresob }_{i}=\sum_{o} \sum_{d}\left[\operatorname{Ltrfl}_{i, o, d} \times\left(C N_{i, o}^{-1}-C N_{l t r}^{-1}\right)\right] .
\end{array}\right\}
$$

Where $i$ and $o$ denote the plant functional type and the type of organ respectively; Ltrfl is the rate of litter fall (g C/(plant-day)); $C_{i, o}$ is the $\mathrm{C}$ pool size of the organ $o ; \eta_{L t r f l, i, o}$ is a parameter that indicates the daily turnover rate of the organ; Nresob (g N/(plant-day)) is the rate of $\mathrm{N}$ resorption; $C N_{i, o}$ and $C N_{l t r}$ are C:N ratio of the live and dead organ $o$ respectively.

\subsection{Maintenance respiration}

Following the approach of Ryan (1991), assuming fixed $Q_{10}$ value of 2.0, the daily maintenance respiration (Rm, $\mathrm{g}$ $\mathrm{C} /($ plant $\cdot$ day $))$ of plant $i$ is calculated as the function of the ambient temperature $T$ :

$$
R m_{i}=\sum_{o}\left(\eta_{R m, i} \times Q_{10, R m}^{\frac{T_{0}-2 s}{10}} \times C_{i, o}\right) .
$$

Where $\eta_{R m, i}$ is the respiration coefficient of PFT $i$, whose value is derived by model calibration; $T_{o}\left({ }^{\circ} \mathrm{C}\right)$ is the ambient temperature of organ $o$. For root, $T_{o}=$ soil temperature; otherwise, $T_{o}=$ air temperature.

\section{Carbon assimilation}

AEM-DV estimates $\mathrm{C}$ assimilation rate following a biochemical model of leaf photosynthesis, originally developed by Farquhar et al. (1980) and subsequently expanded by Collatz et al. (1992) and other researchers (Bonan, 1996; Sellers et al., 1996). Photosynthesis is explicitly connected to stomatal conductance, and controlled by multiple environmental factors, such as temperature and leaf water potential. The photosynthesis rate is first calculated on the leaf level. Assimilation rates $\left(A ; \mu \mathrm{mol} \mathrm{CO} /\left(\mathrm{s} \cdot \mathrm{m}^{2}\right.\right.$ leaf $\left.)\right)$ on a unit-projected leaf-area basis for both $\mathrm{C} 3$ and $\mathrm{C} 4$ plants are estimated independently for the sunlit and shaded canopy fractions. GPP at the canopy level is then derived by multiplying leaf-level photosynthesis rate by leaf area index:

$$
G P P=\text { dayl } \times f_{\text {gpp }, \text { water }} \times\left(L A I_{\text {sunlit }} \times A_{\text {sunlit }}+L A I_{\text {sunilt }} \times A_{\text {shade }}\right) \times 12 \times 10^{6} .
$$

Where $f_{g p p \text {,water }}$ is the effects of a water deficit on productivity. Leaf photosynthesis is the minimum of RuBP carboxylase (Rubisco) limited rate of carboxylation $\left(w_{c}\right)$, the light limited rate of carboxylation $\left(w_{j}\right)$, and the export limited rate of carboxylation $\left(w_{e}\right)$. For $\mathrm{C}_{4} \mathrm{PFT}, w_{e}$ refers to the PEP carboxylase limited rate of carboxylation (Collatz et al., 1992). 


$$
\begin{aligned}
& A=\min \left(w_{c}, w_{j}, w_{e}\right) \text {, } \\
& w_{c}= \begin{cases}\frac{\left(c_{i}-\Gamma_{*}\right) \times V_{\max }}{c_{i}+K_{c} \times\left(1+\frac{O_{2}}{K_{o}}\right)} & \left(C_{3} P F T\right) \\
V \text { max } & \left(C_{4} P F T\right),\end{cases} \\
& w_{j}= \begin{cases}\frac{\left(c_{i}-\Gamma_{*}\right) \times 4.6 \times \alpha \times \operatorname{Rad}_{a b s, P A R}}{c_{i}+2 \times \Gamma_{*}} & \left(C_{3} P F T\right) \\
4.6 \times a \times \operatorname{Rad}_{a b s, P A R} & \left(C_{4} P F T\right),\end{cases} \\
& w_{e}=\left\{\begin{array}{ll}
0.5 \times V_{\max } & \left(C_{3} P F T\right) \\
4000 \times V_{\max } \frac{c_{i}}{\text { Pressure }} & \left(C_{4} P F T\right) .
\end{array}\right\}
\end{aligned}
$$

Where $c_{i}$ and $o_{i}$ are the partial pressure of internal leaf $\mathrm{CO}_{2}$ and $\mathrm{O}_{2}$, respectively (Pa); Pressure is the atmospheric pressure (Pa; see equation A1.6); $\Gamma_{*}$ is the $\mathrm{CO}_{2}$ compensation point (Pa); $K_{c}$ and $K_{o}$ are the Michaelis-Menten constants for $\mathrm{CO}_{2}$ and $\mathrm{O}_{2}$, respectively; absorbed PAR $\left(\operatorname{Rad}_{a b s, P A R}, \mathrm{~W} / \mathrm{m}^{2}\right)$ is converted to photosynthetic photon flux by assuming $4.6 \mu \mathrm{mol}$ photons per Joule; $\alpha$ is the quantum efficiency; $V_{\max }$ is the maximum rate of carboxylation varied with temperature $\left(\mathrm{T},{ }^{\circ} \mathrm{C}\right)$, and the water potential of the crown $\left(\psi_{c r n}, \mathrm{kPa}\right)$ :

$$
V_{\max }=V_{\max 25} \times \alpha_{v \max }^{\frac{T-25}{10}} \times f(T) \times f\left(\psi_{c r n}\right),
$$

Where $V_{\max 25}$ is the maximum carboxylation rate at $25^{\circ} \mathrm{C} ; a_{v \max }$ is a temperature sensitivity parameter, indicating the magnitude of change in $V_{\max }$ with temperature altering every $10^{\circ} \mathrm{C}$ away from the reference temperature $\left(25^{\circ} \mathrm{C}\right) ; f(T)$ is an empirical function that delineates the response of leaf carboxylation to temperature; $f\left(\psi_{c r n}\right)$ is an empirical function that that delineates the response of leaf carboxylation to the leaf water potential.

$$
\begin{aligned}
& f(T)=\frac{\left(T-T_{\min }\right) \times\left(T-T_{\max }\right)}{\left(T-T_{\min }\right) \times\left(T-T_{\max }\right)-\left(T-T_{\text {opt }}\right)^{2}}, \\
& f\left(\psi_{\text {crn }}\right)=\operatorname{Min}\left\{1, \operatorname{Max}\left[0, \frac{\left(\psi_{\text {crn }}-\psi_{\text {close }}\right)}{\left(\psi_{\text {open }}-\psi_{\text {close }}\right)}\right]\right\} .
\end{aligned}
$$

Where $T_{\min }, T_{\max }$ and $T_{\text {opt }}$ are minimum, maximum, and optimum temperature $\left({ }^{\circ} \mathrm{C}\right)$ for photosynthesis respectively; $\psi_{\text {close }}$ and $\psi_{\text {open }}$ are thresholds of crown water potential $(\mathrm{kPa})$ at which stomata of leaf begin to fully close and fully open respectively; $\psi_{c r n}$ is calculated as:

$$
\psi_{c r n}=\sum_{n=1}^{N}\left(\text { Rootfract }_{n} \times \psi_{n}\right)+15 \times H
$$

Where $\mathrm{n}$ denotes the $\mathrm{n}^{\text {th }}$ soil layer; $\psi_{n}(\mathrm{kPa})$ denotes the water potential in soil layer $\mathrm{n}$; Rootfract $_{n}$ denotes the fraction of root biomass in soil layer n; $H(\mathrm{~m})$ is the height of plant. $H=0$ for non-woody plants. Following Friend et al. (1997), AEM-DV assumes that the effective water potential decreases by $15 \mathrm{kPa} / \mathrm{m}$ from soil surface to the top of crown.

\section{Phenology}

The leaf-phenological status of deciduous PFTs is defined as the current fraction of this year's maximum leaf coverage. Users are required to determine the appropriate phenology models and parameters to define the time of leaf onset and offset for each PFT. Furthermore, the span of leaf onset (onset_period, day) from budburst to the maximum leaf coverage status, and the span of leaf offset (offset_period, day) from the beginning of leaf senescence to complete leaf offset. During the leaf onset or offset period, the leaf-phenological status of a deciduous PFT changes by 1/onset_period or 1/offset_period per day, respectively. Following provides a list of the phenology models that is available in the AEM-DV. Table A2 provides default parameters for major PFTs of the world. 


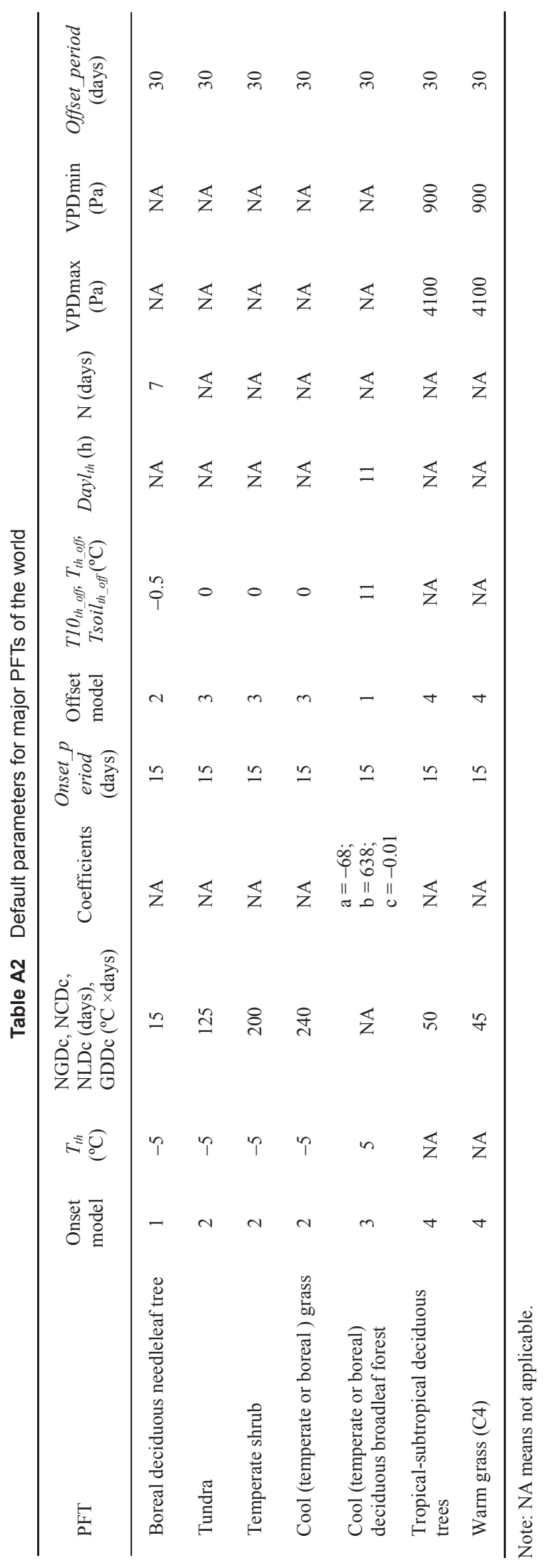




\subsection{Models of leaf onset}

(1) Leaf onset model 1: the critical number of growing days (NGDc)

The leaf onset of these types occurs when the number of days during the preceding two months on which the daily mean air temperature is above a certain threshold $\left(T_{t h},{ }^{\circ} \mathrm{C}\right)$ exceeds a critical value (NGDc). The estimation of NGDc begins on the $1^{\text {st }}$ January in North Hemisphere $(\mathrm{NH})$ and on the $1^{\text {st }}$ July in South Hemisphere $(\mathrm{SH})$.

(2) Leaf onset model 2: the critical growing degree days (GDDc)

First, the GDD is calculated by summing daily mean air temperature above an arbitrary threshold $\left(T_{t h},{ }^{\circ} \mathrm{C}\right)$ for last $\mathrm{N}(\mathrm{N}=20)$ days since the $1^{\text {st }}$ January in $\mathrm{NH}$, and the $1^{\text {st }} \mathrm{July}$ in $\mathrm{SH}$. The leaf onset of these types occurs when GDD is larger than a critical GDD value (GDDc),

$$
G D D=\sum_{J A N 1 s t}^{t} \operatorname{Max}\left(T-T_{t h}, 0\right)
$$

(3) Leaf onset model 3: parallel chilling/heat sum model (Murray et al. 1989)

This model combines heat and chill requirements assuming that an increase in chilling days reduces the plan's GDD requirement. A chilling day has a daily mean air temperature below a particular threshold $\left(T_{t h},{ }^{\circ} \mathrm{C}\right)$. The summery of chilling days (NCD) start from the previous the $1^{\text {st }}$ November for NH (the $3^{\text {rd }}$ May for SH), and the summery of GDD start from the $1^{\text {st }}$ January for $\mathrm{NH}$ (the $1^{\text {st }}$ January. for $\mathrm{SH}$ ). The onset date occurs when the observed GDD exceeds a critical value (GDDc),

$$
\left.\begin{array}{l}
G D D c=a+b \times e^{(c \times N C D)} \\
\text { with } N C D=\text { number of days when } T_{d a y}<T_{t h} \text { since the last } 1^{\text {st }} \text { Nov, }
\end{array}\right\}
$$

where $\mathrm{a}, \mathrm{b}$, and $\mathrm{c}(\mathrm{c}<0)$ are empirical coefficients.

Leaf onset model 4: lag period model of moisture controlled PFTs.

It is assumed that leaf onset lags behind the accumulation of water in the soil, the lags (NLD, or the number of lag day) being specific for each PFTs. We estimate the onset date of the soil hydrological cycle (D) as the first 5-day period with increasing soil moisture. Furthermore, for the 25-day period after the $\mathrm{D}$, the number of days with increasing soil moisture is required to be greater than the number of days with decreasing soil moisture (Botta et al., 2000). Although the starting date of calculation is set to the $1^{\text {st }}$ January in NH, and the $1^{\text {st }}$ July in SH, leaf onset can be initiated after any leaf offset.

\subsection{Models of leaf offset}

(1) Leaf offset model 1: response to daylength and soil temperature

Leaf offset begins when day length and soil temperature drops to less than their thresholds - Dayl $l_{t h}(\mathrm{hr})$ and Tsoil th_off $\left({ }^{\circ} \mathrm{C}\right)$, respectively.

(2) Leaf offset model 2: response to consecutive cold days

Leaf offset begins when temperature stays below a threshold $\left(T_{\text {th_off }},{ }^{\circ} \mathrm{C}\right)$ for a number $(\mathrm{N})$ of consecutive days.

(3) Leaf offset model 3: response to 10-day mean temperature

Following Foley et al. (1996), leaf offset begins when the 10-day mean temperature either falls below a threshold (T10 th_off, $\left.{ }^{\circ} \mathrm{C}\right)$.

(4) Leaf offset model 4: response to the water stress

The estimation of leaf offset is based on the VPD index (iVPD) and plants' NPP value in Jolly et al. (2005).

VPD is vapor pressure deficiency $(\mathrm{Pa})$, calculated as difference between saturation and actual vapor pressure.

$$
\begin{aligned}
i V P D & =0 \quad(V P D \geq V P D \max ) \\
& =1-(V P D-V P D \min ) /(V P D \max -V P D \min ) \\
& =1 . \quad(V P D \leq V P D \text { min })
\end{aligned}
$$

$(V P D \max >V P D>V P D \min )$

To buffer the single extreme events from prematurely triggering canopy changes, the $I V P D$ is calculated as 21-day moving average of daily indicators. The leaf offset will be triggered if VPD $>V P D$ min for five consecutive days and the 10-day mean average NPP of the plant is negative. The defoliation of trees can also be triggered when $i V P D<0.5$. In this case, $5 \%$ of the leave biomass will drop every day, until all leaves are lost or negative NPP is detected. 


\section{References}

Baier W, Robertson G W. 1966. A new versatile soil moisture budget. Canadian Journal of Plant Science, 46: 299-315.

Baker L A, Hope D, Xu Y, et al. 2001. Nitrogen balance for the central Arizona-Phoenix (CAP) ecosystem. Ecosystems, 4: 582-602.

Bonan G B. 1996. A land surface model (LSM version 1.0) for ecological, hydrological, and atmospheric studies: technical description and user's guide. NCAR Technical Note: NCAR/TN-417-STR. Boulder, CO: National Center for Atmospheric Research.

Botta A, Viovy N, Ciais P, et al. 2000. A global prognostic scheme of leaf onset using satellite data. Global Change Biology, 6: 709-725.

Brater E F. 1968. Steps toward a better understanding of urban runoff processes. Water Resources Research, 4: 335-347.

Breuer L, Eckhardt K, Frede H G. 2003. Plant parameter values for models in temperate climates. Ecological Modelling, 169: 237-293.

Cannel M G R. 1984. Woody biomass of forest stands. Forest Ecology and Management, 8: 299-312.

Cannel M G R, Milne R, Hargraeves K J. 1999. National inventories of terrestrial carbon sources and sinks: the U.K. experience. Climatic Change, 42: 505-530.

Cairns M A, Brown S, Helmer E H, et al. 1997. Root biomass allocation in the world's upland forests. Oecologia, 111: 1-11.

Collatz G J, Ribas-Carbo M, Berry J A. 1992. A coupled photosynthesis-stomatal conductance model for leaves of $\mathrm{C}_{4}$ plants. Australian Journal of Plant Physiology, 19: 519-538.

Coughlan J C, Running S W. 1997. Regional ecosystem simulation: a general model for simulating snow accumulation and melt in mountainous terrain. Landscape Ecology, 12: 119-136.

Elhakeem M, Papanicolaou A N. 2009. Estimation of the runoff curve number via direct rainfall simulator measurements in the State of Iowa, USA. Water Resources Management, 23: 2455-2473.

Farquhar G D, von Caemmerer S, Berry J A. 1980. A biochemical-model of photosynthetic $\mathrm{CO}_{2}$ assimilation in leaves of $\mathrm{C}_{3}$ species. Planta, 149: 78-90.

Foley J A, Prentice I C, Ramankutty N, et al. 1996. An integrated biosphere model of land surface processes, terrestrial carbon balance, and vegetation dynamics. Global Biogeochemical Cycles, 10: 603-628.

Friend A D, Stevens A K, Knox R G, et al. 1997. A process-based, terrestrial biosphere model of ecosystem dynamics (Hybrid v3.0). Ecological Modelling, 95: 249-287.

Fulton M R. 1999. Patterns in height-diameter relationships for selected tree species and sites in eastern Texas. Canadian Journal of Forest Research, 29: $1445-1448$.

Gale M R, Grigal D F. 1987. Vertical root distributions of northern tree species in relation to successional status. Canadian Journal of Forest Research, 17: 829-834.

Houghton R A, Hobbie J E, Melillo J M, et al. 1983. Changes in the carbon content of terrestrial biota and soils between 1860 and 1980: a net release of $\mathrm{CO}_{2}$ to the atmosphere. Ecological Monographs, 53: 235-262.

Huang S M, Titus S J, Wiens D P. 1992. Comparison of nonlinear height-diameter functions for major Alberta tree species. Canadian Journal of Forest Research, 22: 1297-1304.

Jackson R B, Mooney H A, Schulze E D. 1997. A global budget for fine root biomass, surface area, and nutrient contents. Proceedings of the National Academy of Sciences of the United States of America, 94: 7362-7366.

Jolly W M, Nemani R, Running S W. 2005. A generalized, bioclimatic index to predict foliar phenology in response to climate. Global Change Biology, 11: 619-632.

Kemp P R, Reynolds J F, Pachepsky Y, et al. 1997. A comparative modeling study of soil water dynamics in a desert ecosystem. Water Resources Research, 33: 73-90.

Larcher W. 1980. Physiological Plant Ecology (1 $1^{\text {st }}$ ed.). New York: Springer-Verlag, 303.

Leemans R, Prentice I C. 1987. Description and simulation of tree-layer composition and size distributions in a primaeval Picea-Pinus forest. Vegetatio, 69: 147-156.

Leemans R, Prentice I C. 1989. FORSKA, A General Forest Succession Model. Uppsala: Institute of Ecological Botany, 70.

Lin B L, Sakoda A, Shibasaki R, et al. 2000. Modeling a global biogeochemical nitrogen cycle in terrestrial ecosystems. Ecological Modelling, 135: $89-110$.

Lohse K A, Hope D, Sponseller R A, et al. 2008. Atmospheric deposition of carbon and nutrients across an arid metropolitan area. Science of the Total Environment, 402: 95-105.

Montaño N M, Jaramillo V J, García-Oliva F. 2007. Dissolved organic carbon affects soil microbial activity and nitrogen dynamics in a Mexican tropical deciduous forest. Plant and Soil, 295: 265-277.

Murray M B, Cannell M G R, Smith R I. 1989. Date of budburst of fifteen tree species in Britain following climatic warming. Journal of Applied 
Ecology, 26: 693-700.

Mustafa M A, DeJong R, Hayhoe H N, et al. 1983. Intermittent infiltration and evaporation from soil columns. Canadian Journal of Soil Science, 63: 303-314.

Noble I R, Crisp M D. 1979. Germination and growth models of short-lived grass and forb populations based on long term photo-point data at Koonamore, South Australia. Israeli Journal of Botany, 28: 195-210.

Oleson K W, Bonan G B, Feddema J, et al. 2008. An urban parameterization for a global climate model. Part II: sensitivity to input parameters and the simulated urban heat island in offline simulations. Journal of Applied Meteorology and Climatology, 47: 1061-1076.

Pacala S W, Canham C D, Silander J A. 1993. Forest models defined by field measurements. I. the design of a northeastern forest simulator. Canadian Journal of Forest Research, 23: 1980-1988.

Panshin A J, de Zeeuw C, Brown H P. 1964. Textbook of Wood Technology: Structure, Identification, Uses, and Properties of the Commercial Woods of the United States. $2^{\text {nd }}$ ed. New York: McGraw-Hill Book Company, 643.

Riedo M, Grub A, Rosset M, et al. 1998. A pasture simulation model for dry matter production, and fluxes of carbon, nitrogen, water and energy. Ecological Modelling, 105: 141-183.

Ryan M G. 1991. Effects of climate change on plant respiration. Ecological Applications, 1: 157-167.

Saxton K E, Rawls W J. 2006. Soil water characteristic estimates by texture and organic matter for hydrologic solutions. Soil Science Society of America Journal, 70: 1569-1578.

Schimel J P, Weintraub M N. 2003. The implications of exoenzyme activity on microbial carbon and nitrogen limitation in soil: a theoretical model. Soil Biology and Biochemistry, 35: 549-563.

Sellers P J, Bounoua L, Collatz G J, et al. 1996. Comparison of radiative and physiological effects of doubled atmospheric $\mathrm{CO}_{2}$ on climate. Science, 271: 1402-1406.

Shinozaki K, Yoda K, Hozumi K. 1964. A quantitative analysis of plant form-the pipe model theory: I. basic analyses. Japanese Journal of Ecology, 14: 97-105.

Sitch S, Smith B, Prentice I C, et al. 2003. Evaluation of ecosystem dynamics, plant geography and terrestrial carbon cycling in the LPJ dynamic global vegetation model. Global Change Biology, 9: 161-185.

Thornton P E, Running S W, White M A. 1997. Generating surfaces of daily meteorological variables over large regions of complex terrain. Journal of Hydrology, 190: 214-251.

Thornton P E, Running S W. 1999. An improved algorithm for estimating incident daily solar radiation from measurements of temperature, humidity, and precipitation. Agricultural and Forest Meteorology, 93: 211-228.

United States Army Corps of Engineers. 1956. Snow Hydrology: Summary Report of the Snow Investigations. Portland (OR): North Pacific Division, Corps of Engineers, United States Army, 437.

United States Department of Agriculture. 1986. Urban Hydrology for Small Watersheds. Technical Release 55. Washington, DC: United States Department of Agriculture, Natural Resources Conservation Service and Conservation Engineering Division, 164.

White M A, Thornton P E, Running S W, et al. 2000. Parameterization and sensitivity analysis of the BIOME-BGC terrestrial ecosystem model: net primary production controls. Earth Interactions, 4: 1-85.

Wigmosta M S, Vail L W, Lettenmaier D P. 1994. A distributed hydrology-vegetation model for complex terrain. Water Resources Research, 30 : $1665-1680$.

World Meteorological Organization. 2008. Guide to Meteorological Instruments and Methods of Observation, Appendix 4B. WMO-No. 8. Geneva: World Meteorological Organization.

Zeide B. 1993. Primary unit of the tree crown. Ecology, 74: 1598-1602. 